\title{
Chemical probing reveals insights into the signaling mechanism of inflammasome activation
}

Yi-Nan Gong ${ }^{1,2}$, Xiaoming Wang ${ }^{2,3}$, Jiayi Wang ${ }^{2,4}$, Zhenxiao Yang ${ }^{2,4}$, Shan $\mathrm{Li}^{2}$, Jieling Yang ${ }^{2}$, Liping Liu ${ }^{2}$, Xiaoguang Lei ${ }^{2,3}$, Feng Shao ${ }^{2}$

${ }^{1}$ College of Life Sciences, Beijing Normal University, Beijing 100875, China $;{ }^{2}$ National Institute of Biological Sciences, \#7 Science Park Rd, Zhongguancun Life Science Park, Beijing 102206, China; ${ }^{3}$ School of Pharmaceutical Science and Technology, Tianjin University, Tianjin 300072, China; ${ }^{4}$ Graduate School of Chinese Academy of Medical Sciences and Peking Union Medical College, Beijing 100730, China

Caspase-1-mediated IL-1 $\beta$ production is generally controlled by two pathways. Toll-like receptors (TLRs) recognize pathogen-derived products and induce NF-кB-dependent pro-IL-1 $\beta$ transcription; NOD-like receptors (NLRs) assemble caspase-1-activating inflammasome complexes that sense bacterial products/danger signals. Through a targeted chemical screen, we identify bromoxone, a marine natural product, as a specific and potent inhibitor of the caspase-1 pathway. Bromoxone is effective over diverse inflammatory stimuli including TLR ligands plus ATP/nigericin, cytosolic DNA, flagellin and Bacillus anthracis lethal toxin. Bromoxone also efficiently suppresses caspase-1 activation triggered by several types of bacterial infection. Bromoxone acts upstream or at the level of the inflammasome in a transcription-independent manner. Bromoxone also inhibits pro-IL-1 $\beta$ expression by targeting components upstream of IKK in the TLR-NF-KB pathway. The unique dual activities of bromoxone are shared by the known TAK1 inhibitor that specifically blocks Nalp3 inflammasome activation. Hinted from the mechanistic and pharmacological properties of bromoxone, we further discover that several known NF- $\kappa B$ inhibitors that act upstream of IKK, but not those targeting IKK or IKK downstream, are potent blockers of different NLRs-mediated caspase-1 activation. Our study uncovers a possible non-transcriptional molecular link between the NLR (Nalp3)-mediated inflammasome pathway and TLR-NF-KB signaling, and suggests a potential strategy to develop new anti-inflammatory drugs.

Keywords: innate immunity; inflammasome; NOD-like receptors; chemical biology; signal transduction

Cell Research (2010) 20:1289-1305. doi:10.1038/cr.2010.135; published online 21 September 2010

\section{Introduction}

The innate immunity system recognizes a wide range of pathogen-derived products, collectively called pathogen-associated molecular patterns (PAMPs), thereby initiating inflammatory responses by secreting cytokines and chemokines. One of the most important inflammatory cytokines secreted by macrophages is IL-1 $\beta$, and ex-

Correspondence: Feng Shao ${ }^{\mathrm{a}}$, Xiaoguang Lei ${ }^{\mathrm{b}}$

${ }^{a}$ Tel: 86-10-80728593; Fax: 86-10-80728046

E-mail: shaofeng@nibs.ac.cn

${ }^{\mathrm{b}}$ Tel: 86-10-80704786; Fax: 86-10-80704785

E-mail: leixiaoguang@nibs.ac.cn

Received 3 August 2010; revised 12 August 2010; accepted 17 August 2010; published online 21 September 2010 cessive IL-1 $\beta$ production is associated with immune disorders such as Muckle-Wells syndrome, familial cold urticaria, and chronic infantile neurological cutaneous and articular syndrome $[1,2]$. IL- $1 \beta$ is first synthesized as an inactive precursor pro-IL-1 $\beta$ [3]. Pro-IL-1 $\beta$ is transcriptionally upregulated upon sensing of PAMPs by Toll-like receptors (TLRs), a class of membrane-associated pattern-recognition receptors [4-6]. For example, bacterial lipopolysaccharide (LPS) and flagellin are recognized by TLR4 and TLR5, respectively, whereas single-stranded viral RNA is the natural ligand of TLR7/TLR8.

Pro-IL-1 $\beta$ transcription is controlled by the NF- $\kappa \mathrm{B}$ pathway downstream of TLRs. NF- $\kappa B$ is critical for many innate immunity and death/survival-related cellular processes [7, 8]. Engagement of TLRs by PAMPs triggers the sequential activation of the TAK1 and IKK 
kinase complexes. Activated IKK complex in turn phosphorylates I $\kappa \mathrm{B}$ family of NF- $\kappa \mathrm{B}$ inhibitors. Phosphorylated $\mathrm{I} \kappa \mathrm{B}$ proteins are then ubiquitinated and degraded in the proteasome, which releases the NF- $\mathrm{BB}$ dimer into the nucleus to turn on gene expression. The NF- $\mathrm{KB}$ pathway has been heavily explored as a promising drug target, and many chemical inhibitors of NF- $\mathrm{KB}$ activation have been discovered or developed (www.nf-kb.org).

Pro-IL-1 $\beta$, as well as IL-18, is processed into the mature form by caspase- $1[9,10]$. Active caspapse- 1 consisting of two heterodimers of p20 and p10 subunits is generated from the $\mathrm{p} 45$ precursor through autocatalytic cleavage [11]. Inflammatory stimuli induce autoprocessing and activation of caspase- 1 through large cytoplasmic complexes called inflammasomes [2]. Assembly of the inflammasome is mediated by another family of pattern-recognition receptors known as NOD-like receptors (NLRs) $[12,13]$. The inflammasome not only senses microbial products, but also recognizes danger signals such as extracellular ATP and monosodium urate microcrystals that could be generated upon tissue injury or other pathological dysfunctions. The best-studied NLR protein Nalp3 (also called NLRP3 or cryopyrin) functions together with the adaptor ASC to mediate caspase-1 activation in response to diverse stimuli including TLR ligands plus extracellular ATP [14, 15], lysosomal damage triggered by insoluble materials such as silica, asbestos, amyloid- $\beta$, urate crystals and aluminum [16-21], and viral nucleic acid [22]. It has been recently suggested that the TLR signaling licenses the Nalp3 inflammasome activation through NF- $\mathrm{KB}$-dependent transcriptional upregulation of Nalp3 [17, 21-28]. The IPAF (also known as NLRC4) inflammasome perceives cytosolic flagellin and induces caspase- 1 activation in ASC-independent manner $[27,29]$. The Nalp1b inflammasome in mouse macrophages responds to the metalloprotease activity of Bacillus anthracis lethal toxin (LT) [30]. The non-NLR protein AIM2 serves as a receptor for cytosolic dsDNA and activates caspase-1 through ASC [25, 28, 31-34].

Bacterial infection of macrophages also triggers caspase-1 activation. Salmonella, Legionella and Pseudomonas aeruginosa all can stimulate the IPAF inflammasome activation [27, 35-42]. Legionella-induced caspase-1 activation involves an additional NLR protein NAIP5 (also called Birc1e) $[29,39,43]$. Depending on the multiplicity of infection, Shigella flexneri activates the IPAF or Nalp3 inflammasome [44, 45]. Present understandings about inflammasome-mediated caspase- 1 activation are largely derived from genetic studies in mice, and signaling events downstream of different inflammatory stimuli to inflammasome assembly/activation are poorly understood.
In this study, we employ small molecules-based chemical approaches to probe the caspase- 1 pathway. We identify bromoxone, a potent marine natural product inhibitor of caspase- 1 activation and inflammatory cell death triggered by diverse stimuli in human and mouse macrophages. Our investigation of pharmacological properties of bromoxone reveals a possible nontranscriptional control of Nalp3 inflammasome activation by the TLR-NF- $\mathrm{KB}$ axis, which requires the TAK1 kinase in the case of TLR-stimulated Nalp3 activation. Similarly to bromoxone that efficiently suppresses inflammation induced by multiple types of bacterial infection, several known NF- $\kappa B$ inhibitors acting upstream of IKK are further identified as potent inhibitors of the inflammasome pathway. Our study suggests a potential strategy to develop new anticaspase-1 activation agents using the existing pool of NF- $\kappa \mathrm{B}$ inhibitors.

\section{Results}

Identification of bromoxone as a potent caspase-1 pathway inhibitor

Inspired by the universal role of phosphorylation in signal transduction, we started our chemical screen by testing effects of a panel of 24 frequently used kinase inhibitors (Supplementary information, Table S1) on Nalp3mediated caspase-1 activation triggered by LPS plus ATP (LPS/ATP) in THP-1 cells. We also included several other interesting compounds in the screen including a widely used necrosis inhibitor necrostatin-1, a mitochondrial division inhibitor Mdivi-1, an immunosuppressant cyclosporin A that targets mitochondrial cyclophilin as well as an unknown-function marine natural product known as bromoxone (bromoxone refers to bromoxone 1 illustrated in Figure 1A hereafter) [46-48]. None of the kinase inhibitors except for AKT inhibitor IV (compound 4 in Figure 1B) prevented LPS/ATP-induced caspase-1 activation in THP-1 cells (Figure 1B; Supplementary information, Figure S1). However, this inhibitor caused massive cell death within $1 \mathrm{~h}$ of drug administration (data not shown), and another AKT inhibitor Triciribine failed to suppress caspase-1 activation (compound 5 in Figure 1B). Unexpectedly, we found that bromoxone could efficiently block caspase-1 activation at the concentration of about $1 \mu \mathrm{M}$ (Figure 1B and 1C). Bromoxone did not block staurosporine-induced apoptosis and caspase- 3 activation (Figure 1D), and had little effects on the viability of THP1 cells (Figure 1E; Supplementary information, Figure S2), even at a higher concentration of $2.5 \mu \mathrm{M}$. The specific activity of bromoxone on inflammasome activation was verified by a microscopy-based assay using a cellpermeable caspase-1 fluorescent substrate (Figure 1F). 
<smiles>O=C1C(Br)=C[C@H](O)[C@H]2O[C@H]12</smiles>

Bromoxone 1
B

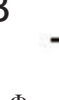

LPS+ATP

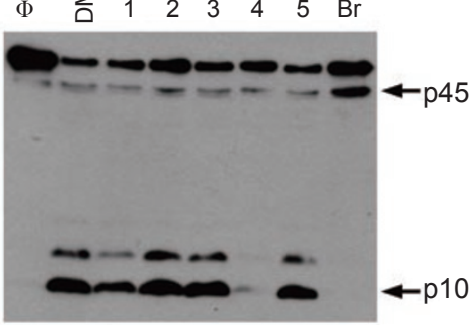

C

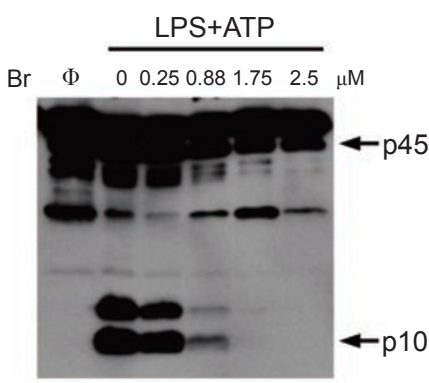

D

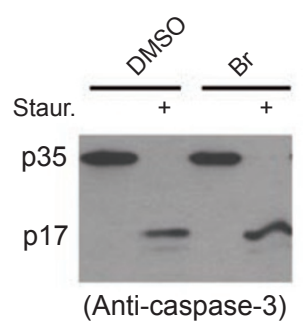

E

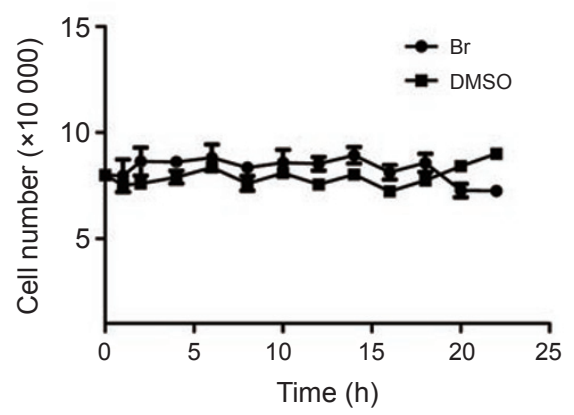

$\mathrm{F}$

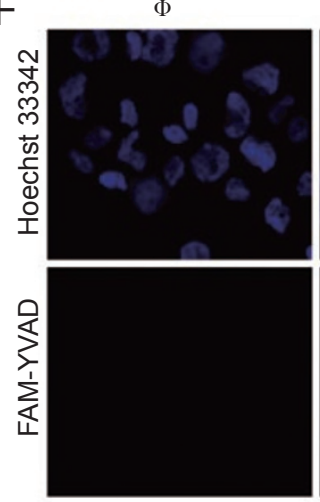

$(2.95 \pm 0.78 \%)$

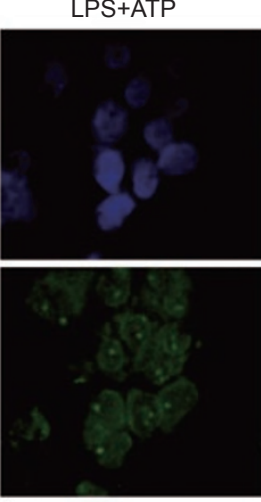

$(59.78 \pm 15.32 \%)$

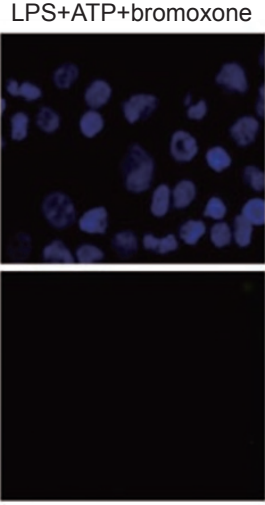

$(5.09 \pm 1.01 \%)$

Figure 1 Identification of bromoxone as a caspase-1 pathway inhibitor. (A) Chemical structure of bromoxone. (B, C) PMAdifferentiated THP-1 cells were left untreated $(\Phi)$ or stimulated with LPS for $3 \mathrm{~h}$ followed by 30 min pulse with 5 mM ATP in the presence of indicated compounds $(\mathbf{B})$ or the indicated concentration of bromoxone (C). Information for compound 1-5 was detailed in Supplementary information, Table S1. Br is short for bromoxone. Shown are caspase-1 immunoblots of the TCA precipitates of culture supernatants. p45, inactive pro-caspase-1; $p 10$, subunit of autoprocessed active caspase-1. (D) HeLa cells were treated with $4 \mu \mathrm{M}$ staurosporine (Staur.) for $4 \mathrm{~h}$ in the presence of bromoxone or DMSO. Cell lysates were blotted with the caspase-3 antibody. p35 and p17 mark pro-caspase-3 and the cleaved caspase-3, respectively. (E) PMA-differentiated THP-1 cells were cultured in the presence or absence of $2.5 \mu \mathrm{M}$ bromoxone for indicated time durations. Numbers of live cell were determined by the CellTiter-Glo Luminescent Cell Viability Assay that measures the ATP level. Note: differentiated THP-1 cells lose the ability to proliferate as expected. (F) PMA-differentiated THP-1 cells were stimulated with LPS/ATP as described in (B) in the absence or presence of $2.5 \mu \mathrm{M}$ bromoxone. Cells were stained with Hoechst 33342 to visualize nuclei, and a cell-permeable fluorescence dye FAM-YVAD-FMK to assay caspase-1 activation. Statistics of percentages of cells showing caspase-1 activation are shown in the parentheses.

Bromoxone blocks inflammatory cell death and formation of the ASC pyroptosome without inhibiting reactive oxygen species (ROS) production

LPS/ATP-stimulated Nalp3 inflammasome activation triggers a necrotic cell death response [13]. Using the Trypan blue staining assay reporting cell membrane integrity, we found that bromoxone completely blocked LPS/ATP-triggered cell death (Figure 2A). Consistently, release of two classical indicators of necrotic cell death, lactate dehydrogenase (LDH) and HMGB1, was also reduced to the control level by bromoxone treatment (Figure $2 \mathrm{~B}$ and $2 \mathrm{C}$ ). Thus, bromoxone could inhibit LPS/ATPstimulated cell death in addition to blocking caspase-1 activation.

LPS/ATP-triggered inflammasome activation features formation of the so-called pyroptosome structure, a large supramolecular assembly of ASC that is believed to mediate caspase- 1 activation $[10,49,50]$. Immunostaining of the endogenous ASC in THP-1 cells showed that the LPS/ATP-triggered ASC pyroptosome formation was completely abolished by bromoxone (Figure 2D). The absence of the pyroptosome staining is not because of bromoxone inhibition of cell death because we have another unreported compound that can block cell death, but not formation of the ASC pyroptosome structure (data not shown). Thus, bromoxone inhibition of LPS/ 

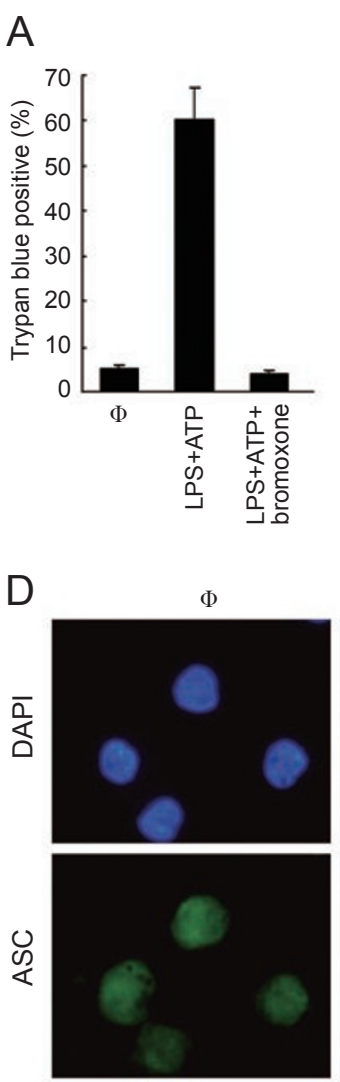

$(2.01 \pm 0.21 \%)$
B $\quad$ C
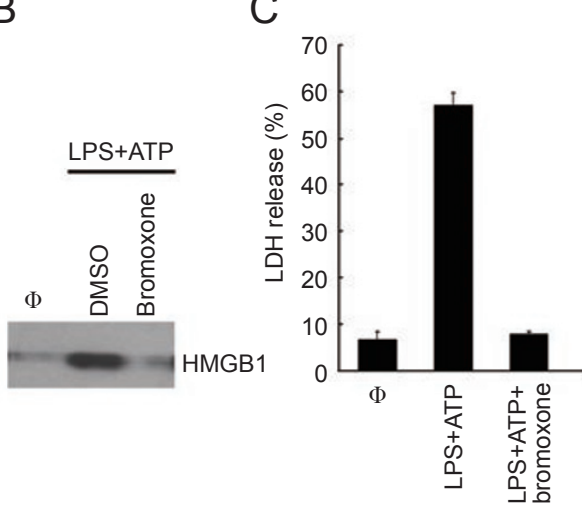

LPS+ATP
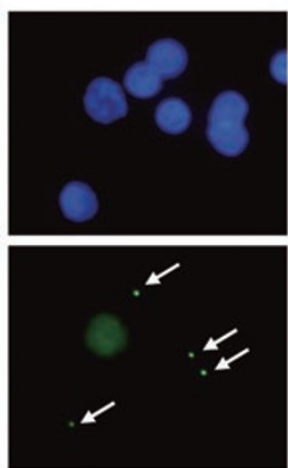

$(32.00 \pm 3.19 \%)$

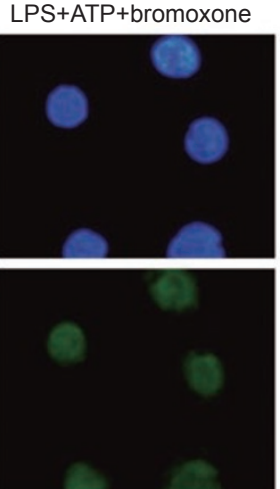

$(1.74 \pm 0.40 \%)$
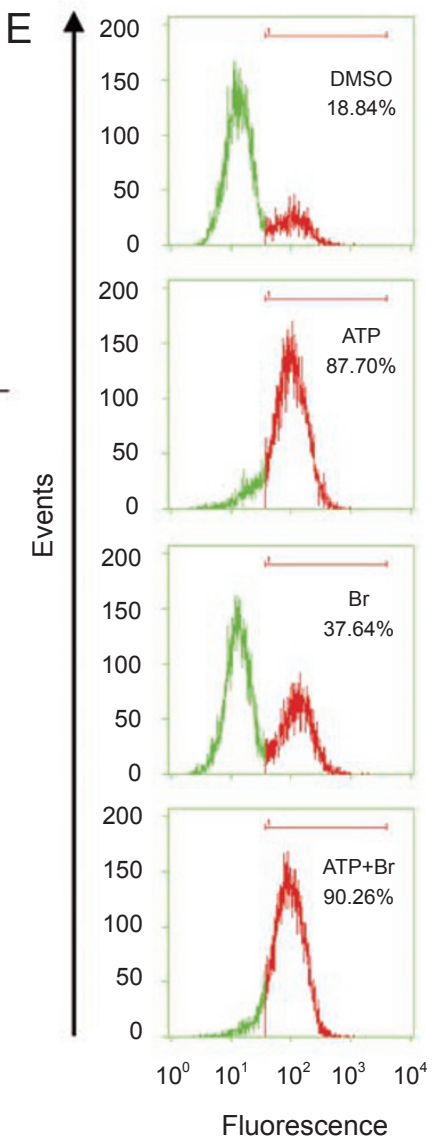

Figure 2 Bromoxone blocks LPS/ATP-triggered inflammatory cell death and formation of the ASC pyroptosome without inhibiting ROS production. (A-C) PMA-differentiated THP-1 cells were stimulated with LPS/ATP in the absence or presence of 2.5 $\mu \mathrm{M}$ bromoxone. Cells were stained with Trypan blue and statistics of percentages of Trypan blue-positive cells are shown in (A). HMGB1 released into the culture media is shown by the anti-HMGB1 immunoblot (B), and the LDH release is shown in (C). (D) PMA-differentiated THP-1 cells were stimulated with LPS/ATP in the absence or presence of $2.5 \mu \mathrm{M}$ bromoxone. Arrowhead marks the ASC pyroptosome stained by the ASC antibody. Statistics of percentages of cells showing the pyroptosome structure are presented in the parentheses. (E) PMA-differentiated THP-1 cells were stimulated with or without ATP (5 mM) for $30 \mathrm{~min}$ in the presence of DMSO or bromoxone $(2.5 \mu \mathrm{M})$, and ROS production was monitored with the fluorescent probe $\mathrm{H}_{2}$ DCFDA by FACS.

ATP-triggered Nalp3 inflammasome activation likely occurs upstream of ASC. ROS production is associated with caspase- 1 activation and has been suggested to be upstream of LPS/ATP-triggered Nalp3 inflammasome assembly. However, bromoxone did not inhibit ATPinduced ROS production in THP-1 (Figure 2E) and J774 cells (Supplementary information, Figure S3).

\section{Activities of several bromoxone analogues}

To gain insights into the structure-activity relationship (SAR) of bromoxone, we synthesized several related analogues including bromoxone acetate 2 , ent-bromoxone 3, bromoxone isomer 4 and ent-bromoxone isomer 5 (Figure $3 \mathrm{~A}$ ) based on our previously reported protocols
$[51,52]$. Structural validation and NMR spectra of these derivatives are described in Supplementary information, Data S1. Similarly to bromoxone, none of these derivatives showed detectable toxic effects on THP-1 cells (Supplementary information, Figure S2B and S2C). In contrast to ent-bromoxone 3, bromoxone isomer 4 and ent-bromoxone isomer 5 (Figure 3B), bromoxone acetate 2 (Ac-bromoxone) largely lost the activity of inhibiting LPS/ATP-stimulated caspase-1 processing (Figure 3C) and cell death (data not shown) at the same dose used for bromoxone. The SAR was confirmed by measuring the $\mathrm{IC}_{50}$ of bromoxone $(\sim 0.17 \mu \mathrm{M})$ and its derivatives using the IL-1 $\beta$ ELISA assay (Figure 3D). These data suggest that the free hydroxyl moiety in bromoxone is critical for 
A<smiles>CC(=O)O[C@H]1C=C(Br)C(=O)[C@H]2O[C@@H]12</smiles>

Bromoxone acetate 2<smiles>O=C1C(Br)=C[C@H](O)[C@H]2O[C@H]12</smiles>

Bromoxone isomer 4<smiles>O=C1C(Br)=C[C@H](O)C2OC12</smiles>

ent-bromoxone 3<smiles>O=C1C(Br)=C[C@H](O)C2OC12</smiles>

ent-bromoxone isomer 5
D

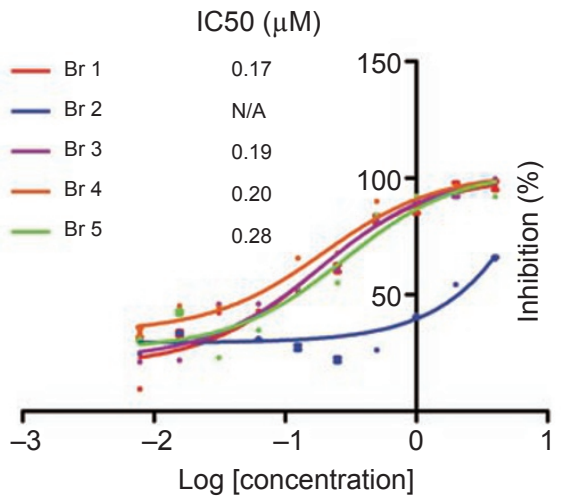

B

C

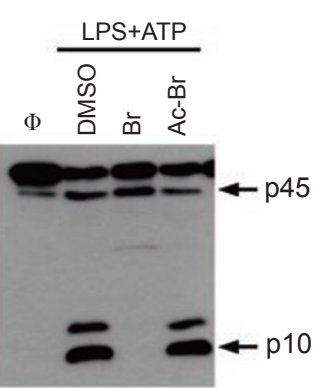

$E$

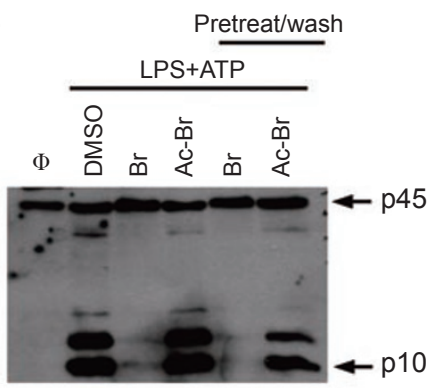

Figure 3 Chemical structures and activities of bromoxone analogues. (A) Chemical structures of synthetic bromoxone analogues. (B, C) PMA-differentiated THP-1 cells were stimulated with LPS/ATP in the absence or presence of $2.5 \mu \mathrm{M}$ bromoxone or its analogues depicted in (A). $\mathrm{Br}$ in (B) is short for bromoxone. Br-3, 4 and 5 in (B) represent ent-bromoxone 3, bromoxone isomer 4 and ent-bromoxone isomer 5, respectively. $\mathrm{Ac}-\mathrm{Br}$ in (C) refers to bromoxone acetate 2. (D) PMA-differentiated THP-1 cells were stimulated with LPS/ATP with different concentrations of indicated bromoxone or its derivatives. The $\mathrm{IC}_{50}$ was determined by measuring the level of secreted IL-1 $\beta$. Note: for bromoxone acetate 2 , the inhibition curve could not be fitted due to loss of the activity. (E) PMA-differentiated THP-1 cells were stimulated as in Figure 1B. For the washout assay, cells pretreated with bromoxone or Ac-bromoxone for 90 min were washed for three times prior to LPS/ATP stimuli.

its anti-inflammatory function of inhibiting macrophage caspase- 1 activation and the stereochemistry appears not to be important.

We also determined whether bromoxone pretreatment alone was sufficient to inhibit caspase- 1 processing. THP-1 cells pretreated with bromoxone for $1.5 \mathrm{~h}$ were washed for three times with serum-free medium. Under this condition, further addition of LPS/ATP failed to induce caspase-1 activation (Figure 3E). This indicates that bromoxone likely functions in a chemically irreversible manner.

Bromoxone is a broad-spectrum inhibitor for different inflammasome-mediated caspase-1 activation

The Nalp3 inflammasome responds to multiple TLR ligands. Bromoxone, but not Ac-bromoxone, could similarly block caspase- 1 activation triggered by the TLR1/2 agonist $\mathrm{Pam}_{3} \mathrm{CSK}_{4}$ or TLR7 agonist R848 and ATP (Figure 4A and 4B). Bromoxone efficiently suppressed caspase-1 autoprocessing induced by LPS plus nigericin, a toxin triggering cytosolic potassium efflux (Figure 4C). Crystal or particle uptake such as in the case of aluminum adjuvant (alum) treatment is another signal that induces Nalp3 inflammasome activation through lysosomal disruption [20]. Again, bromoxone, but not Ac-bromoxone, was effective in blocking caspase-1 activation induced by a lysosome-damaging dipeptide LeuLeu-OMe (Figure 4D). We further examined the effects of bromoxone on high-concentration PMA-differentiated THP-1 cells that do not require TLR engagement. Consistently, bromoxone blocked IL-1 $\beta$ maturation in response to various stimuli including ATP, nigericin, alum 


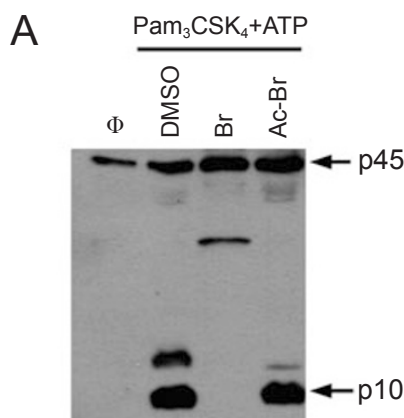

B

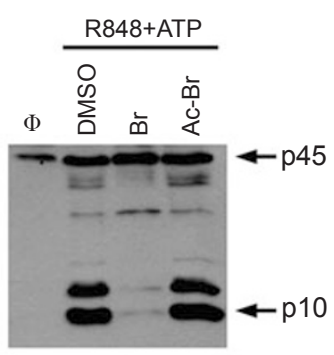

C

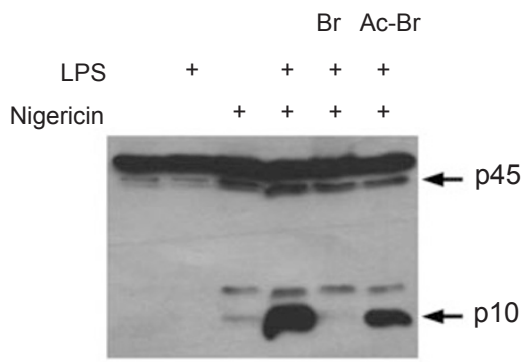

D

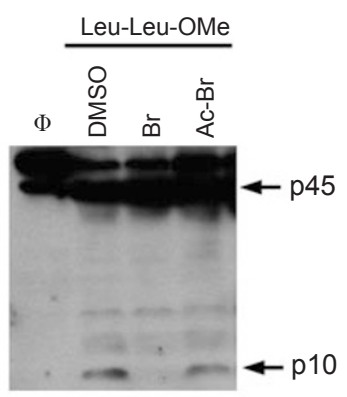

$\mathrm{F}$

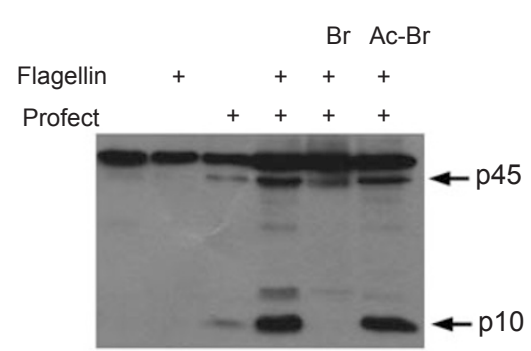

$E$

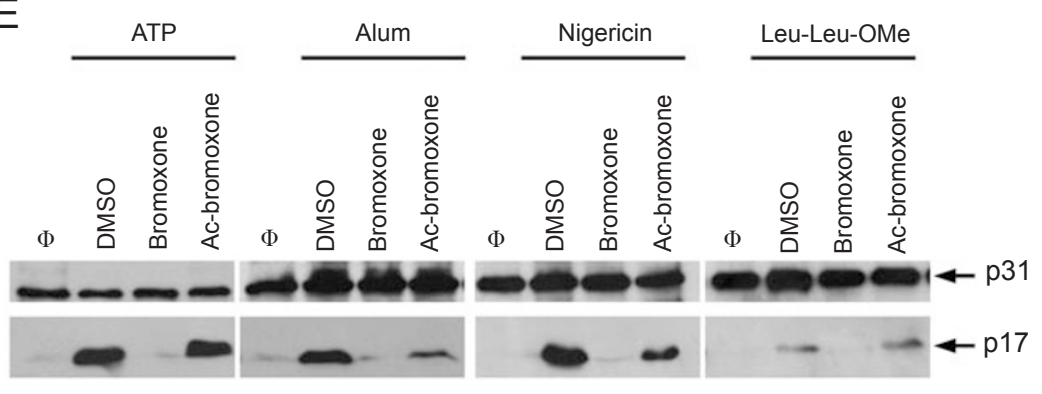

G
$\mathrm{H}$

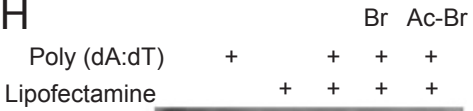

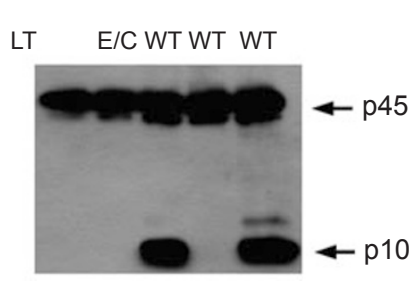

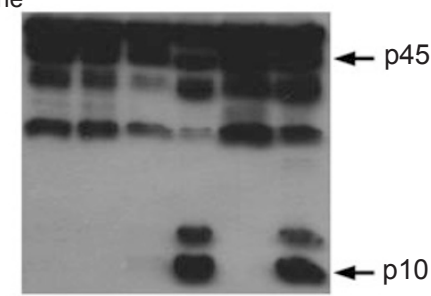

Figure 4 Bromoxone is a broad-spectrum inhibitor for caspase-1 activation induced by diverse inflammatory stimuli. (A, B) PMA-differentiated THP-1 cells were stimulated with $\mathrm{Pam}_{3} \mathrm{CSK}_{4}$ (A) or R848 (B) for $3 \mathrm{~h}$ and then pulsed with $5 \mathrm{mM}$ ATP for $30 \mathrm{~min}$ in the presence of $2.5 \mu \mathrm{M}$ bromoxone $(\mathrm{Br})$ or Ac-bromoxone $(\mathrm{Ac}-\mathrm{Br})$. TCA precipitates of culture supernatants were immunoblotted with the caspase-1 antibody. (C) BMMs derived from 129 mice were stimulated with LPS for $3 \mathrm{~h}$ followed by $45 \mathrm{~min}$ pulse of nigericin $(20 \mu \mathrm{M})$ in the presence of $2.5 \mu \mathrm{M}$ bromoxone $(\mathrm{Br})$ or Ac-bromoxone (Ac-Br). (D) PMA-differentiated THP-1 cells were stimulated with $10 \mathrm{mM}$ Leu-Leu-OMe for $5 \mathrm{~h}$ in the presence of $2.5 \mu \mathrm{M}$ bromoxone $(\mathrm{Br})$ or Ac-bromoxone (Ac-Br). (E) THP-1 cells were differentiated with a high concentration of PMA (100 nM, overnight) to bypass the LPS prime step. The cells were then stimulated with ATP, alum, nigericin or Leu-Leu-OMe in the presence of $2.5 \mu \mathrm{M}$ bromoxone or Acbromoxone. Shown are anti-IL-1 $\beta$ immunoblots of the total cell lysates. p31 and p17 refer to pro-IL-1 $\beta$ and mature IL-1 $\beta$, respectively. (F) BMMs derived from 129 mice were transfected with $3 \mu \mathrm{g}$ flagellin using the Profect $\mathrm{P} 1$ in the presence of 2.5 $\mu \mathrm{M}$ bromoxone $(\mathrm{Br})$ or $\mathrm{Ac}$-bromoxone $(\mathrm{Ac}-\mathrm{Br})$. The culture supernatants were collected $5 \mathrm{~h}$ after transfection and analyzed for caspase-1 activation as shown in other panels. (G) BMMs derived from 129 mice were treated with $1 \mu \mathrm{g} / \mathrm{ml}$ anthrax lethal toxin (LT) (WT or its catalytic mutant E687C [E/C]) plus $1 \mu \mathrm{g} / \mathrm{ml}$ protective antigen for $3 \mathrm{~h}$ in the presence of $2.5 \mu \mathrm{M}$ bromoxone $(\mathrm{Br})$ or Ac-bromoxone (Ac-Br). (H) PMA-differentiated THP-1 cells were transfected with $2 \mu \mathrm{g}$ of poly (dA:dT) by lipofectamine in the presence of $2.5 \mu \mathrm{M}$ bromoxone $(\mathrm{Br})$ or Ac-bromoxone $(\mathrm{Ac}-\mathrm{Br})$. The culture supernatants were collected $7 \mathrm{~h}$ after transfection and analyzed for caspase-1 activation as shown.

and Leu-Leu-OMe (Figure 4E). These results establish that bromoxone is a general inhibitor of the Nalp3 inflammasome pathway independent of TLR ligand priming.

Moreover, bromoxone blocked caspase-1 processing triggered by transfection of purified flagellin (Figure $4 \mathrm{~F}$ ). Lethal toxin treatment of J774 mouse macrophages or bone marrow macrophages (BMMs) that harbor a functional Nalp $1 \mathrm{~b}$ allele induced prominent caspase-1 activation, and this activation was sensitive to bromox- 
one treatment (Figure 4G). Bromoxone was also effective over the AIM2 inflammasome-mediated caspase-1 activation triggered by transfection of plasmid DNA or the synthetic poly (dA:dT) (Figure 4H). Ac-bromoxone was inactive in all three assays described above (Figure $4 \mathrm{~F}-4 \mathrm{H})$. Thus, bromoxone is broad-spectrum and blocks caspase- 1 activation mediated by diverse NLR proteins, which is different from the type 2 diabetes drug glyburide that is specific for the Nalp3 inflammasome [53]. These data together also implicate the existence of a common signaling component/mechanism shared by stimuli of different NLRs.

Bromoxone is not a direct caspase-1 inhibitor and does not affect other cellular processes

Several lines of evidence suggest that bromoxone is unlikely to be a direct caspase-1 inhibitor. Bromoxone treatment completely abolished the ASC pyroptosome formation that is considered to be upstream of caspase-1 activation (Figure 2D). Spontaneous caspase-1 activation in THP-1 cell extracts, though sensitive to the caspase-1specific inhibitor FMK-YVAD, was resistant to bromox- one (Figure $5 \mathrm{~A}$ ). Cleavage of pro-IL-1 $\beta$ by caspase- 1 activated in THP-1 cell extracts was not affected by the presence of bromoxone (Figure 5B). Bromoxone had no effects on auto-activation of caspase- 1 that resulted from over-production in $293 \mathrm{~T}$ cells (Figure 5C). Finally, bromoxone failed to block caspase-1 activation mediated by Nalp3 and AIM2 inflammasome partially reconstituted in 293T cells (Figure 5D). Thus, we conclude that bromoxone is not a direct caspase-1 inhibitor.

Moreover, bromoxone caused no DNA damages and had no visible effects on actin cytoskeleton structure and normal morphologies of several intracellular organelles including mitochondria, endoplasmic reticulum and Golgi apparatus (Supplementary information, Figure S4).

\section{Bromoxone inhibits the $N F-\kappa B$ pathway activation up-} stream of IKK

IL-1 $\beta$ maturation and secretion is a key event downstream of inflammasome-mediated caspase- 1 activation. As expected, production of mature IL-1 $\beta$ (p17) upon LPS/ATP stimulation was largely diminished by bromoxone (Figure 6A). Interestingly, level of the precur-
A

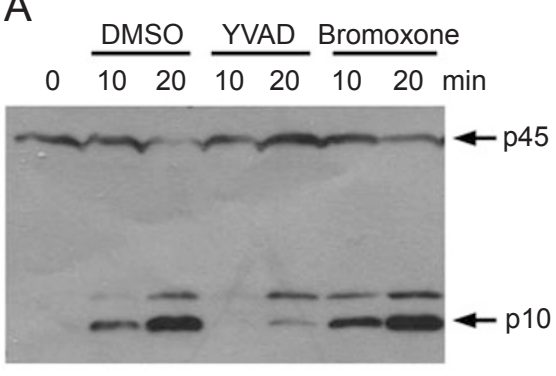

C

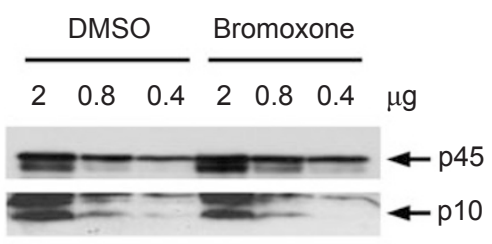

D

B

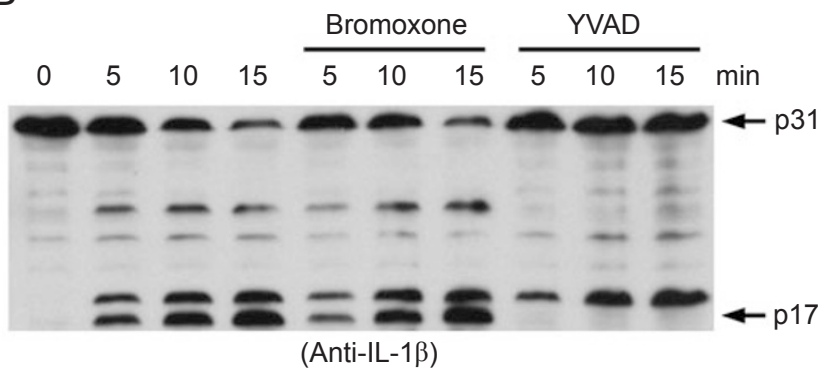

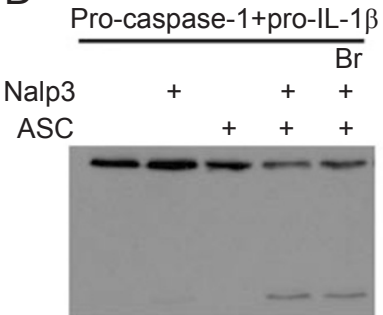

$($ Anti-IL-1 $\beta)$

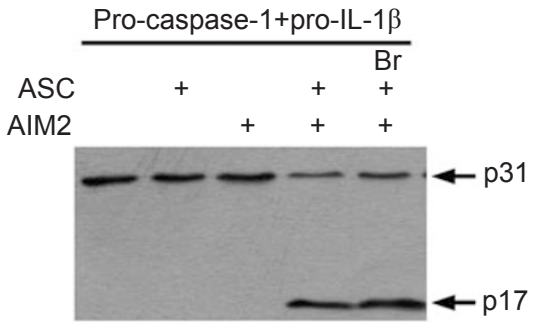

(Anti-IL-1 $\beta)$

Figure 5 Bromoxone does not directly target caspase-1. (A) THP-1 cell extracts were incubated at $30{ }^{\circ} \mathrm{C}$ for indicated time durations in the presence of $2.5 \mu \mathrm{M}$ bromoxone, or $100 \mu \mathrm{M}$ YVAD-FMK, or DMSO alone. Caspase-1 activation was monitored by anti-caspase-1 immunoblotting. (B) THP-1 cell extracts were mixed with cell extracts of 293T cells expressing pro-IL-1 $\beta$ and incubated at $30^{\circ} \mathrm{C}$ in the absence or presence of $10 \mu \mathrm{M}$ bromoxone (or $100 \mu \mathrm{M}$ YVAD-FMK as a positive control). Caspase-1 activation was monitored by anti-IL-1 $\beta$ immunoblotting as shown. (C) 293T cells transfected with different amounts of pro-caspase-1 plasmid were treated with $2.5 \mu \mathrm{M}$ bromoxone or DMSO for $16 \mathrm{~h}$. Cell lysates were analyzed by anti-caspase-1 immunoblotting. (D) 293T cells were transfected with pro-IL-1 $\beta$ and pro-caspase-1 plasmid together with ASC/Nalp3 (left panel), ASC/AIM2 (right panel) expression plasmid. Bromoxone was added at $5 \mathrm{~h}$ after transfection and cells were harvested $21 \mathrm{~h}$ later. Shown are IL-1 $\beta$ immunoblots of the cell lysates. p31 and p17 mark pro-IL-1 $\beta$ and mature IL-1 $\beta$, respectively. 


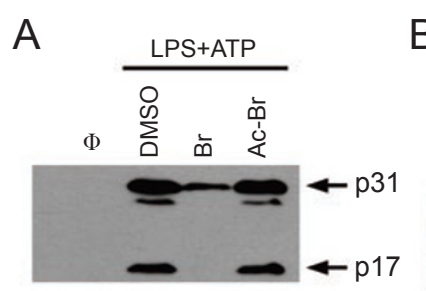

(Anti-IL-1 $\beta$ )
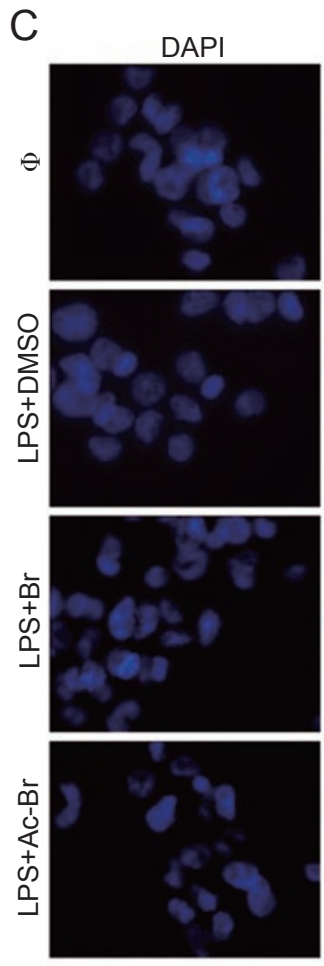
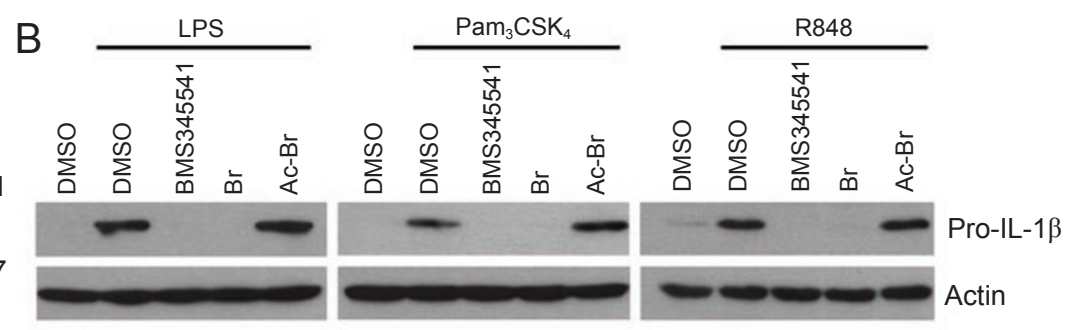

D
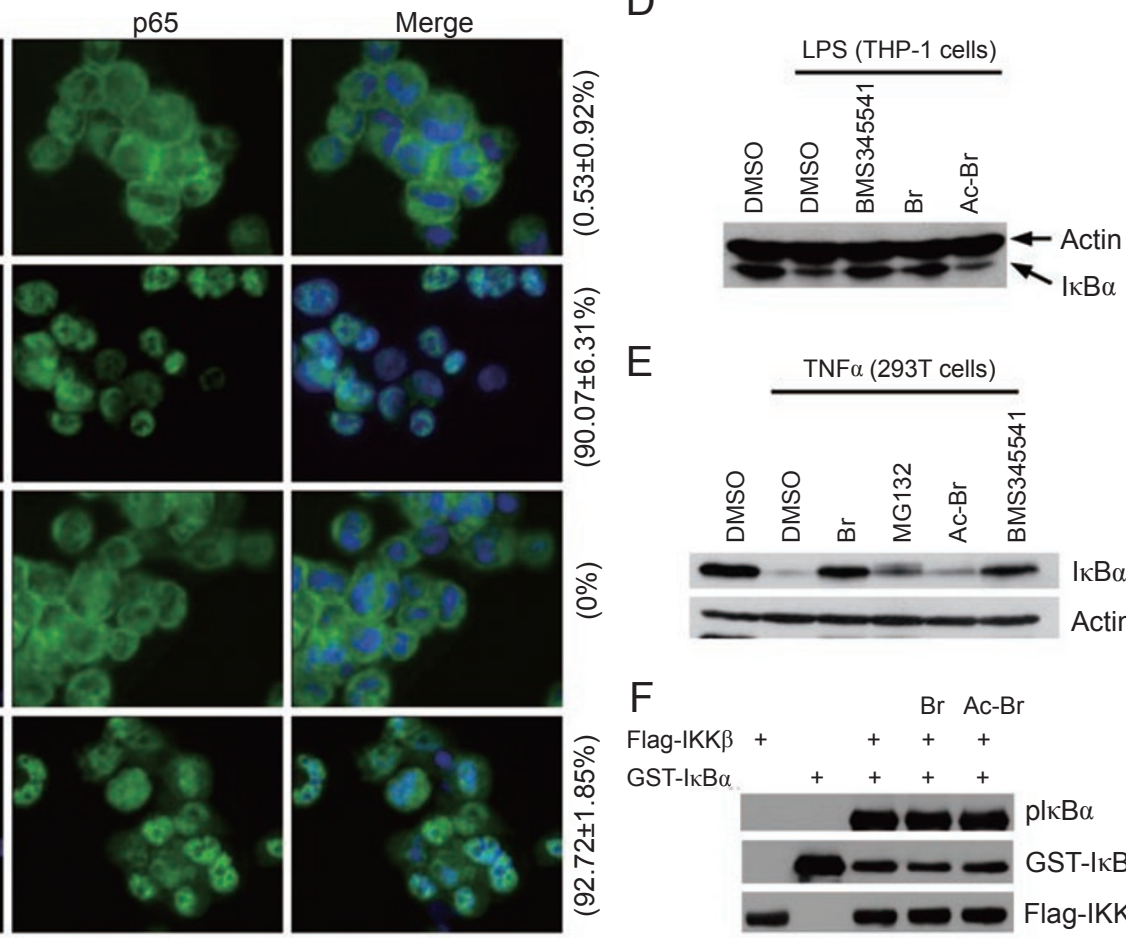
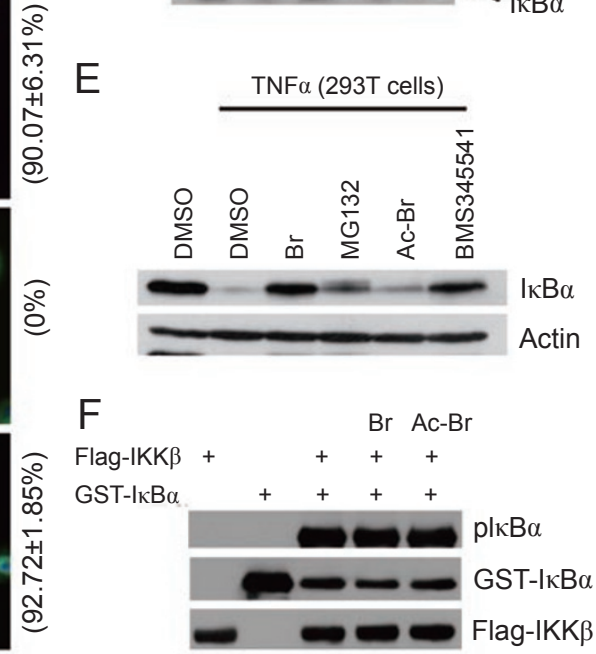

Figure 6 Bromoxone inhibits the NF-kB signaling pathway upstream of IKK. (A) PMA-differentiated THP-1 cells were stimu-

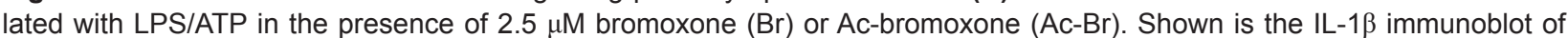
the TCA precipitates of cell supernatants. $\mathrm{p} 31$ and $\mathrm{p} 17$ refer to pro-IL-1 $\beta$ and mature IL-1 $\beta$, respectively. (B) PMA-differentiated THP-1 cells were stimulated with LPS $\left(5 \mu \mathrm{g} / \mathrm{ml}\right.$ ) (left panels), $\mathrm{Pam}_{3} \mathrm{CSK}_{4}(2 \mu \mathrm{g} / \mathrm{ml})$ (middle panels) or R848 $(2 \mu \mathrm{g} / \mathrm{ml})$ (right panels) for $3 \mathrm{~h}$ in the presence of indicated compounds. Total cell lysates were blotted with the IL-1 $\beta$ or actin antibody. (C) PMA-differentiated THP-1 cells were stimulated with LPS $(5 \mu \mathrm{g} / \mathrm{ml})$ for $1 \mathrm{~h}$ in the presence of indicated compounds. Shown are immunofluorescence staining of NF-kB p65 subunit (green) and DAPI staining of nuclei (blue). Statistics of cells with nuclear-localized p65 are listed in the parentheses. (D) PMA-differentiated THP-1 cells were stimulated with LPS (5 $\mu \mathrm{g} / \mathrm{ml})$ for $30 \mathrm{~min}$ in the presence of indicated compounds. Total cell lysates were blotted with I $\mathrm{KB} \alpha$ and actin antibodies. (E) 293T cells were stimulated with TNF $\alpha(20 \mathrm{ng} / \mathrm{ml})$ for $30 \mathrm{~min}$ in the presence of indicated compounds. Total cell lysates were blotted with $I \kappa \mathrm{B} \alpha$ and actin antibodies. (F) Phosphorylation of GST- I $\mathrm{KB} \alpha$ by immunopurified Flag-IKK $\beta$ in the presence or absence of 2.5 $\mu \mathrm{M}$ bromoxone $(\mathrm{Br})$ or Ac-bromoxone $(\mathrm{Ac}-\mathrm{Br})$.

sor pro-IL-1 $\beta$ (p31) in the cell culture supernatant was also dramatically decreased (Figure 6A). Consistently, bromoxone markedly blocked intracellular pro-IL-1 $\beta$ expression stimulated by TLR ligands including LPS, $\mathrm{Pam}_{3} \mathrm{CSK}_{4}$ and R848 in the absence of ATP (Figure $6 \mathrm{~B})$. The NF- $\kappa \mathrm{B}$ pathway signals TLR activation to pro-IL-1 $\beta$ transcription [54], and a known IKK inhibitor BMS345541 totally abolished pro-IL-1 $\beta$ expression induced by any of the three PAMPs (Figure 6B). These data suggest that bromoxone is an inhibitor of the NF$\kappa \mathrm{B}$ signaling downstream of TLR stimulation. We also examined the effects of bromoxone on anisomycin- and PMA-stimulated phosphorylation of c-Jun N-terminal kinases (JNK) and extracellular signal-regulated kinases (Erk1/2), respectively, and found that bromoxone did not inhibit mitogen-activated protein kinase (MAPK) path- 
ways (Supplementary information, Figure S5A and S5B).

The ubiquitin-proteasome system is critical for activation of the NF- $\mathrm{KB}$ signaling. However, bromoxone did not exhibit any inhibitory activity on the ubiquitinproteasome pathway (Supplementary information, Figure S5C and S5D). We then checked several critical signaling steps in the NF- $\mathrm{kB}$ pathway. LPS treatment of THP-1 cells induced a striking p65 nuclear translocation, which was completely inhibited by bromoxone (Figure 6C). Degradation of I $\mathrm{KB} \alpha$ upstream of p65 nuclear translocation was also inhibited by bromoxone in LPS-stimulated THP-1 cells (Figure 6D) as well as in TNF $\alpha$-treated 293T (Figure 6E). Bromoxone did not affect the activity of IKK $\beta$ kinase to phosphorylate I $\mathrm{BB} \alpha$ (Figure $6 \mathrm{E}$ ). These data suggest that bromoxone likely targets components upstream of the IKK complex to block the NF- $\kappa B$ signaling.

Notably, similarly to that observed with inhibiting inflammasome-mediated caspase- 1 activation, acetylation of the hydroxyl group in bromoxone eliminated its activity in blocking PAMPs-induced pro-IL- $1 \beta$ upregulation (Figure 6B) and NF- $\kappa \mathrm{B}$ activation (p65 nuclear translocation and I $\kappa \mathrm{B} \alpha$ degradation) (Figure $6 \mathrm{C}-6 \mathrm{E}$ ).

Bromoxone blocks Nalp3 inflammasome activation independently of its inhibition of $N F-\kappa B$-dependent transcription

In mouse BMM cells, activation of the Nalp3 inflammasome requires TLR engagement (Figure 7A) and TLR-NF- $\kappa$ B-mediated transcription $[23,55]$. IL- $1 \beta$ maturation induced by ATP, nigericin, alum, or Leu-LeuOMe in high-concentration PMA- differentiated THP-1 cells, which does not involve TLR stimulation, was still sensitive to bromoxone treatment (Figure 4E). This indicates that bromoxone inhibition of inflammasome activation is not due to the block of NF- $\mathrm{kB}$-dependent transcription. To further test this idea, we first treated mouse macrophages with LPS for $3 \mathrm{~h}$ and drugs were added for $15 \mathrm{~min}$ prior to the 30 -min pulse of ATP. Following this drug administration scheme, both the protein synthesis inhibitor $\mathrm{CHX}$ and bromoxone had little effects on LPS-stimulated and NF- $\kappa \mathrm{B}$-dependent TNF $\alpha$ and Nalp3 expression (Figure 7B). However, only bromoxone, but not $\mathrm{CHX}$, was still able to block caspase-1 activation efficiently (Figure 7B).

Further supporting the above hypothesis is bromoxone inhibition of Nalp3 inflammasome activation in the THP-1 cell system (Figure 1B). Different from that in mouse BMM cells, LPS stimuli does not upregulate Nalp3 expression and LPS-induced ASC pyroptosome formation is not affected by CHX block of translation in THP-1-derived macrophage cells $[49,56]$. Thus, THP-1 cells appear to express high-level Nalp3 constitutively and can bypass the requirement of NF- $\mathrm{KB}$-stimulated Nalp3 expression, a scenario similar to UV irradiationinduced Nalp3/Asc inflammasome activation in keratinocytes [57]. Consistent with this idea, $\mathrm{CHX}$ at $160 \mu \mathrm{M}$ showed little inhibitions on LPS/ATP-triggered caspase-1 activation although it blocked NF- $\mathrm{KB}$-dependent pro-IL$1 \beta$ expression at much lower concentrations (Figure 7C). However, LPS priming is still required for ATP-triggered caspase- 1 activation in THP-1 cells, and a specific TLR4 inhibitor (Supplementary information, Figure S6) efficiently blocked this activation (Figure 7D) $[58,59]$. Thus, the effectiveness of bromoxone in THP-1 cells supports the idea that it blocks Nalp3 inflammasome activation in a manner independent of its inhibition of NF$\kappa \mathrm{B}$-dependent transcription.

TAK1, but not the downstream NF- $\kappa B$ signaling, controls Nalp3 inflammasome activation in a transcriptionindependent manner

The fact that bromoxone blocks IKK-upstream NF$\kappa \mathrm{B}$ signaling as well as Nalp3 inflammasome activation in a transcription-independent manner prompted us to examine a panel of established $\mathrm{NF}-\mathrm{\kappa B}$ inhibitors (Figure $7 \mathrm{G}$ ) using the THP-1 system. CAPE and JSH-23 block nuclear translocation of the NF- $\kappa \mathrm{B}$ dimer; MG132 suppresses I $\mathrm{B} \alpha \alpha$ degradation; BMS345541 and wedelolactone are two well-established IKK inhibitors $[60,61]$ and 5Z-7-oxozeaenol is a TAK1-specific inhibitor. As expected, all the inhibitors blocked NF- $\kappa \mathrm{B}$-dependent pro-IL-1 $\beta$ expression (Figure 7E). Significantly, inhibitors that target IKK or its downstream (CAPE, JSH-23, MG-132, BMS345541 and wedelolactone) had little effects on LPS/ATP-induced caspase-1 activation (Figure $7 \mathrm{E}$ ), confirming that THP-1 cells do not require NF-кBdependent transcription for Nalp3 inflammasome activation. In contrast, the TAK1 inhibitor 5Z-7-oxozeaenol exhibited an efficient inhibitory activity on LPS/ATPstimulated caspase-1 activation (Figure 7E). Consistently, knockdown of TAK1 by TAK1-specific siRNA in THP-1 cells attenuated LPS/ATP-triggered caspase-1 activation (Figure 7F). These data suggest that TAK1, but not downstream NF- $\kappa \mathrm{B}$ pathway components, is essential for TLR4-sensitized Nalp3 inflammasome activation in THP-1 cells.

We further investigated the role of TAK 1 in inflammasome activation induced by other stimuli. As shown in Figure 8A, 5Z-7-oxozeaenol efficiently blocked caspase- 1 activation triggered by LPS plus nigericin, alum or Leu-Leu-OMe. 5Z-7-oxozeaenol was also effective in inhibiting caspase- 1 activation induced by ATP plus other TLR ligands including $\mathrm{Pam}_{3} \mathrm{CSK}_{4}$ and R848 (Figure 8B) 

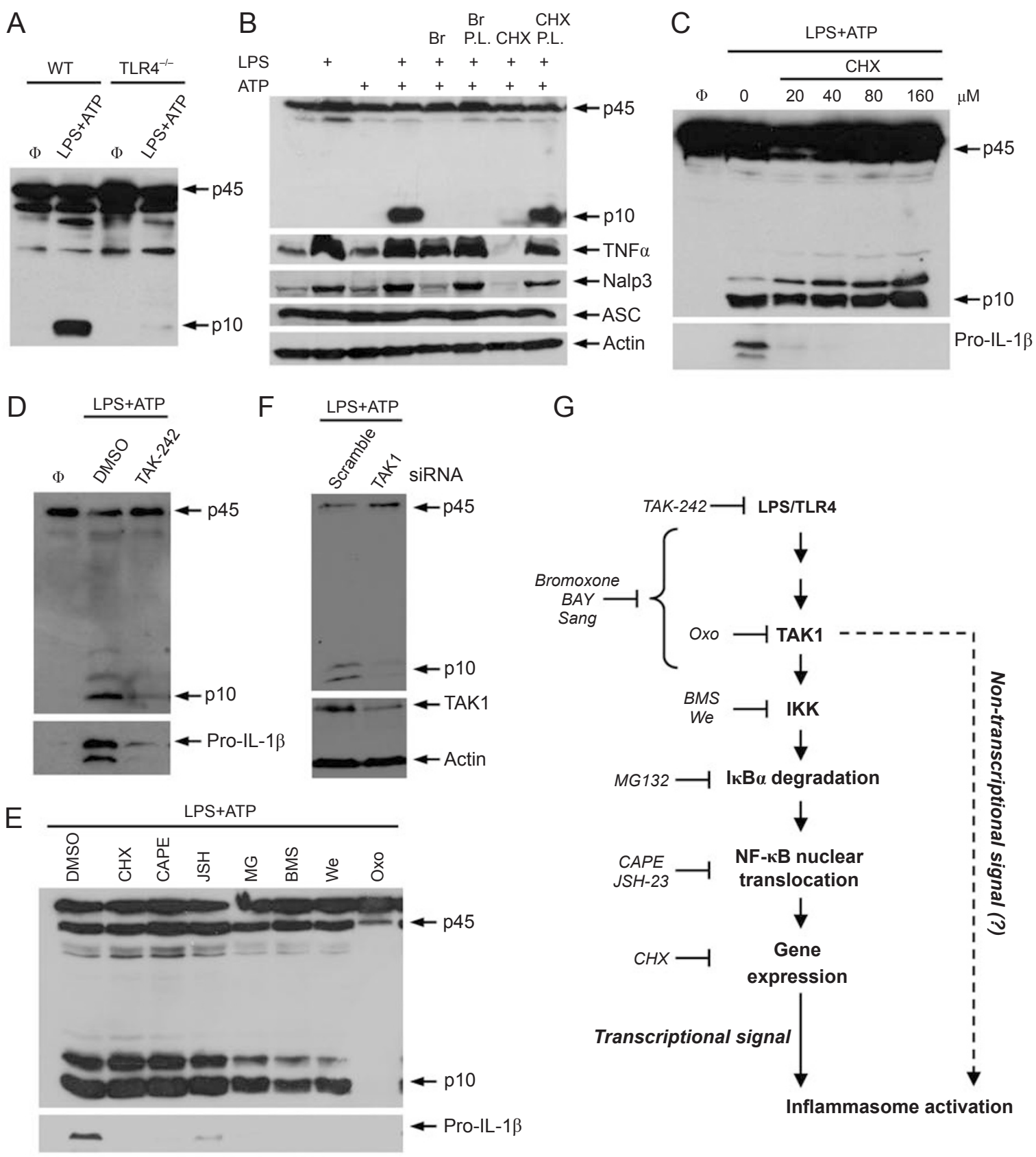

Figure 7 Bromoxone blocks Nalp3 inflammasome activation in a transcription-independent manner and effects of other NF$\kappa B$ inhibitors on Nalp3 inflammasome activation. (A) BMMs from either C57BL/6 (WT) or C57BL/10ScNJ (TLR4 ${ }^{-/-}$, a natural deletion mutant) were stimulated with LPS/ATP. Shown is the caspase-1 immunoblot of culture supernatants. (B) Immortalized macrophages were treated with LPS/ATP. Br P.L. and CHX P.L. mean that the drugs (bromoxone and cycloheximide, 2.5 $\mu \mathrm{M}$ and $160 \mu \mathrm{M}$, respectively) were added $3 \mathrm{~h}$ after LPS stimulation (prior to ATP pulse) to prevent transcriptional inhibition. The TCA precipitates of culture supernatants were immunoblotted with caspase- 1 and TNF $\alpha$ antibodies, and the total cell lysates were blotted with Nalp3, ASC and actin antibodies. (C-E) PMA-differentiated THP-1 cells were stimulated with LPS/ ATP in the presence of indicated compounds. Shown are caspase- 1 and IL-1 $\beta$ immunoblots of culture supernatants. (C) $\mathrm{CHX}$, cycloheximide with indicated increasing concentrations. (D) TAK-242, $20 \mu \mathrm{M}$. (E) CHX, $160 \mu \mathrm{M}$; CAPE, $50 \mu \mathrm{M}$; JSH, JSH-23, $50 \mu \mathrm{M}$; MG, MG132, $50 \mu \mathrm{M}$; BMS, BMS345541, $50 \mu \mathrm{M}$; We, wedelolactone, $40 \mu \mathrm{M}$; Oxo, 5Z-7-oxozeaenol, $1 \mu \mathrm{M}$. (F) PMA-differentiated THP-1 cells were transfected with either scramble siRNA or siRNA targeting human TAK1, and then stimulated with LPS/ATP. Shown are caspase-1 immunoblots of cell supernatants, and TAK1 and actin immunoblots of total cell lysates. (G) A schematic summary of possible signaling connections between inflammasome activation and the TLR-NF$\kappa \mathrm{B}$ axis revealed by chemical probing using marked compounds. Note: the NF- $\mathrm{BB}-$ dependent transcriptional control of inflammasome activation is bypassed in THP-1 cells. 
A

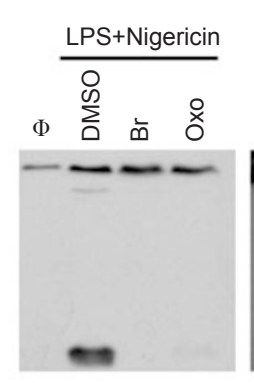

C

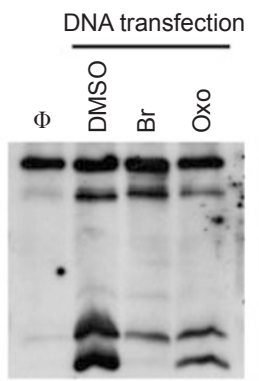

Anthrax lethal toxin

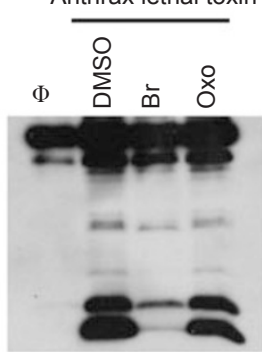

Flagellin transfection

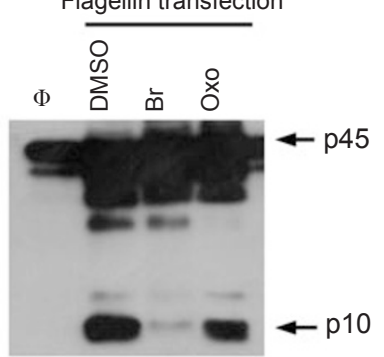

B

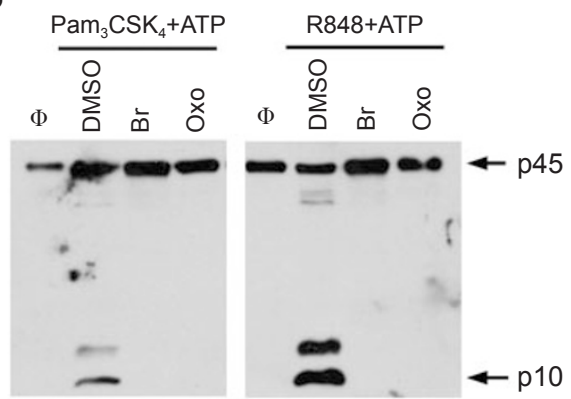

D

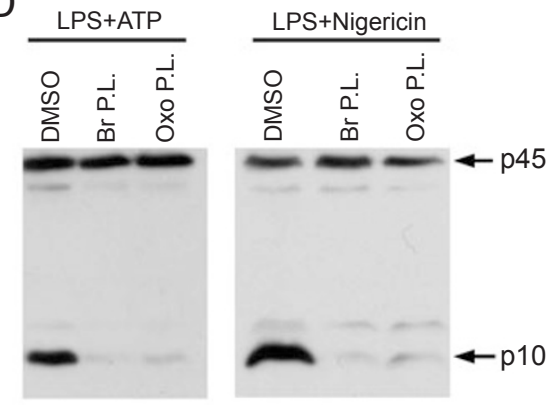

Figure 8 The TAK1 inhibitor 5Z-7-oxozeaenol specifically inhibits Nalp3 inflammasome activation also in a transcriptionindependent manner. (A) BMMs derived from C57BL6 mice were stimulated with LPS plus Nigericin (40 $\mu$ M), Leu-Leu-OMe (1.5 $\mathrm{mM})$ or alum $(600 \mu \mathrm{g} / \mathrm{ml})$ in the presence of $5 Z-7$-oxozeaenol $(O x o, 0.5 \mu \mathrm{M})$ or bromoxone $(2.5 \mu \mathrm{M})$. Shown are caspase-1 immunoblots of cell supernatants. (B) PMA-differentiated THP-1 cells were stimulated with either Pam $\mathrm{CSK}_{4}$ or R848 for $3 \mathrm{~h}$ and then pulsed with $5 \mathrm{mM}$ ATP for $30 \mathrm{~min}$ in the presence of $1 \mu \mathrm{M}$ 5Z-7-oxozeaenol (Oxo) or $2.5 \mu \mathrm{M}$ bromoxone. The TCA precipitates of cell supernatants were immunoblotted with the caspase-1 antibody. (C) BMMs from 129 mice were stimulated with DNA transfection, anthrax lethal toxin, and flagellin transfection in the presence of indicated compounds. Shown are caspase-1 immunoblots of the TCA precipitates of cell supernatants. Br, bromoxone, $2.5 \mu \mathrm{M}$, Oxo, 5Z-7-oxozeaenol, 0.5 $\mu \mathrm{M}$. (D) Immortalized macrophages were stimulated with LPS/ATP or LPS/nigericin with or without 5Z-7-oxozeaenol. Br P.L. and Oxo P.L. mean that bromoxone $(2.5 \mu \mathrm{M})$ and $5 Z$-7-oxozeaenol $(1 \mu \mathrm{M})$, respectively, were added $3 \mathrm{~h}$ after LPS stimulation (before ATP or nigericin treatment). The TCA precipitates of cell supernatants were immunoblotted with the caspase- 1 antibody.

as well as TNFR ligand TNF $\alpha$ (data not shown). Different from bromoxone, 5Z-7-oxozeaenol showed little inhibitions on TLR-independent caspase- 1 activation such as that mediated by DNA transfection, anthrax lethal toxin and bacterial flagellin stimuli (Figure 8C). Thus, 5Z-7-oxozeaenol appears to be a specific inhibitor for the Nalp3 inflammasome pathway. All the 5Z-7-oxozeaenolsensitive inflammasome stimuli require TAK1 to activate downstream NF- $\kappa B$ signaling. Similarly to bromoxone, inhibition of Nalp3 inflammasome by 5Z-7-oxozeaenol was independent of NF- $\mathrm{BB}$-dependent transcription as shown by using the "post-LPS" drug administration scheme (Figure 8D). Thus, we have identified two inhibitors, bromoxone and the TAK1-specific 5Z-7-oxozeaenol, both of which are IKK-upstream NF- $\kappa$ B pathway blockers and efficiently inhibit Nalp3 inflammasome activation in a transcription-independent manner.

We were curious about whether bromoxone could directly target TAK1. Addition of purified TAK1/TAB1 complex induces IKK-dependent phosphorylation of I $\kappa \mathrm{B} \alpha$ in cell-free extracts [62], but this was not inhibited by bromoxone (Supplementary information, Figure S7A). Bromoxone did not affect the TAK1/TAB1/TAB2 complex formation in a co-immunoprecipitation assay (Supplementary information, Figure S7B). These suggest that TAK1 is unlikely to be the direct target of bromoxone and confirm that bromoxone acts upstream of IKK.

\section{Block of bacterial infection-triggered inflammasome activation by bromoxone and potential pharmacological implications \\ Given that bromoxone is a potent and broad-spectrum inhibitor of the inflammasome/caspase-1 pathway, we examined whether it is effective in inhibiting bacte- rial infection-induced caspase-1 activation. Legionella pneumophila infection of lung macrophages causes Le-}


gionnaire's disease with pneumonia symptoms [63, 64]. Infection of mouse BMM cells with wild-type L. pneumophila (lp02), but not the type IV secretion-deficient mutant (lp03), induced evident caspase-1 activation [38, 43]. Similarly, diarrhea-causing enteric bacteria EPEC and $S$. flexneri infection also induce caspase-1 activation in a manner dependent of their type III secretion systems. Bromoxone, but not Ac-bromoxone, efficiently suppressed caspase-1 activation induced by L. pneumophila, EPEC and Shigella infection (Figure 9A-9C). Bromoxone did not affect the viability of the three pathogens along the infection course (Supplementary information, Figure S8). These results demonstrate the potent antiinflammatory activity of bromoxone in protecting macrophages from pathogen infection-triggered caspase-1 activation.

Both bromoxone and 5Z-7-oxozeaenol, the two inflammasome pathway inhibitors we identified, target the TLR-NF- $\kappa B$ signaling upstream of the IKK complex. This promoted us to explore the possibility of identifying more inflammasome pathway inhibitors from the existing pool of NF- $\kappa$ B blockers. BAY-11-7082 inhibits the cytokine-inducible I $\kappa \mathrm{B} \alpha$ phosphorylation without affecting the IKK kinase activity [65]; sanguinarine completely blocks I $\mathrm{KB} \alpha$ phosphorylation and degradation induced by TNF and IL-1, but not that by $\mathrm{H}_{2} \mathrm{O}_{2}$ and ceramide [66]. As expected, both drugs did not inhibit the kinase activity of IKK $\beta$ (Figure 9D). Notably, BAY-11-7082 and sanguinarine shared the activity of bromoxone in inhibiting caspas- 1 activation and pro-IL- $1 \beta$ expression in LPS/ATP-treated THP-1 cells at the concentration previously used to block the NF-kB pathway (Figure 9E). The two drugs also blocked or attenuated LPS/ATP-induced cell death responses (Figure 9F). Interestingly, BAY-117082 and sanguinarine blocked DNA transfection- and flagellin-induced caspase-1 activation, and BAY-11-7082 could also block lethal toxin-triggered caspase-1 activation (Figure 9G). Thus, these results serve as a proof of principle for the feasibility of pharmacological dissection of the inflammasome signaling and development of new anti-inflammatory drugs using the existing pool of NF$\kappa \mathrm{B}$ pathway inhibitors.

\section{Discussion}

Inflammasome activation triggered by TLR ligands was originally thought to be independent of TLR and its downstream NF- $\mathrm{KB}$ signaling. The concept has been revised by two recent studies proposing that the TLR$\mathrm{NF}-\kappa \mathrm{B}$ pathway licenses Nalp3 inflammasome assembly by transcriptionally upregulating Nalp3 expression $[23,55]$. Here, we provide three lines of evidence that raise a possible new hypothesis that the TLR-NF- $\kappa B$ axis also directly signals inflammasome activation in addition to the regulation through gene transcription. First, we showed that bromoxone could block LPS/ATPstimulated caspase-1 activation without disturbing the $\mathrm{NF}-\kappa \mathrm{B}-$-responsive gene expression in mouse BMM cells. Second, the LPS-TLR4-NF- $\kappa B$ signaling is essential for Nalp3 activation in THP-1 cells that have bypassed the requirement of NF- $\kappa \mathrm{B}-$ dependent transcription. Third, among a collection of the TLR-NF- $\kappa B$ pathway inhibitors, only those acting upstream of the IKK complex were found to suppress LPS/ATP-stimulated caspase-1 activation. The above hypothesis is further extended by our identification of TAK1 as a new signaling component specifically mediating TLR-induced non-transcriptional activation of the Nalp3 inflammasome. As for the role of TAK1 in Nalp3 activation, one possible idea is that TAK1, in response to TLR4 activation, may directly phosphorylate Nalp3 or another critical component in the Nalp3 complex such as the newly identified TXNIP protein [67].

The mode of the possible non-transcriptional regulation by the TLR-NF- $\kappa \mathrm{B}$ axis is likely unique to Nalp3 inflammasome activation. Activation of the Nalp1b inflammasome by anthrax lethal toxin does not require any TLR and NF-kB-dependent gene transcription. Neither TLR5 (the flagellin sensor) nor TLR9 (the DNA sensor) plays a role in the IPAF and AIM2 inflammasome activation, respectively. The TAK1 inhibitor 5Z-7-oxozeaenol could not inhibit either lethal toxin- or flagellin- induced caspase-1 activation.

Bromoxone is a new chemical inhibitor of the inflammasome caspase-1 pathway. ASC is the only known component required for multiple NLRs to mediate caspase-1 activation [2]. However, bromoxone could block ASC-independent and IPAF-mediated caspase-1 activation; the Nalp3-ASC and AIM2-ASC-caspase-1 pathways reconstituted in $293 \mathrm{~T}$ cells escaped from inhibition by bromoxone; and ASC does not play a role in the NF$\kappa \mathrm{B}$ signaling branch that is sensitive to bromoxone. These lines of evidence rule out the possibility of ASC as the target of bromoxone. We speculate that bromoxone may target a yet-to-be-identified "common" signaling step that is shared among NLR-mediated inflammatory responses and serves as a converging point downstream of different inflammatory stimuli. This would be reminiscent of signaling events downstream of different TLRs that share signaling components such as the Myd88/ TRIF family of adaptors. Alternatively, bromoxone may target an unknown signal that is parallel to the ligandNLR-caspase-1 pathway and serves as a "gatekeeper" for inflammasome-mediated caspase- 1 activation. Our ongo- 
A

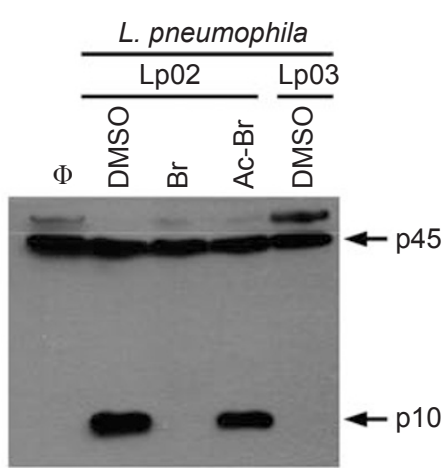

B

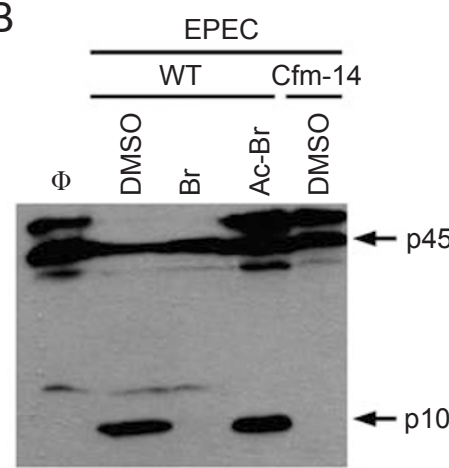

C

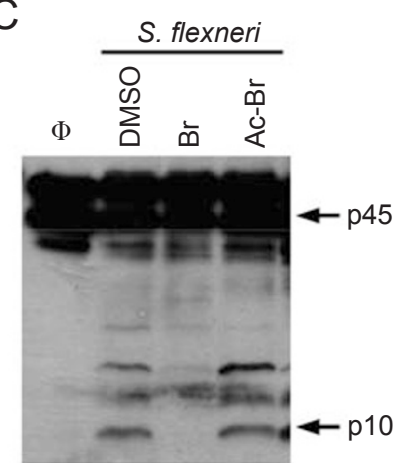

D

$E$

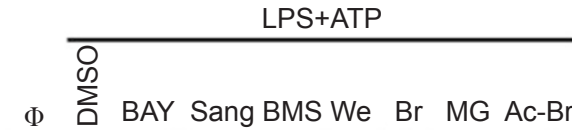

BAY Sang BMS We
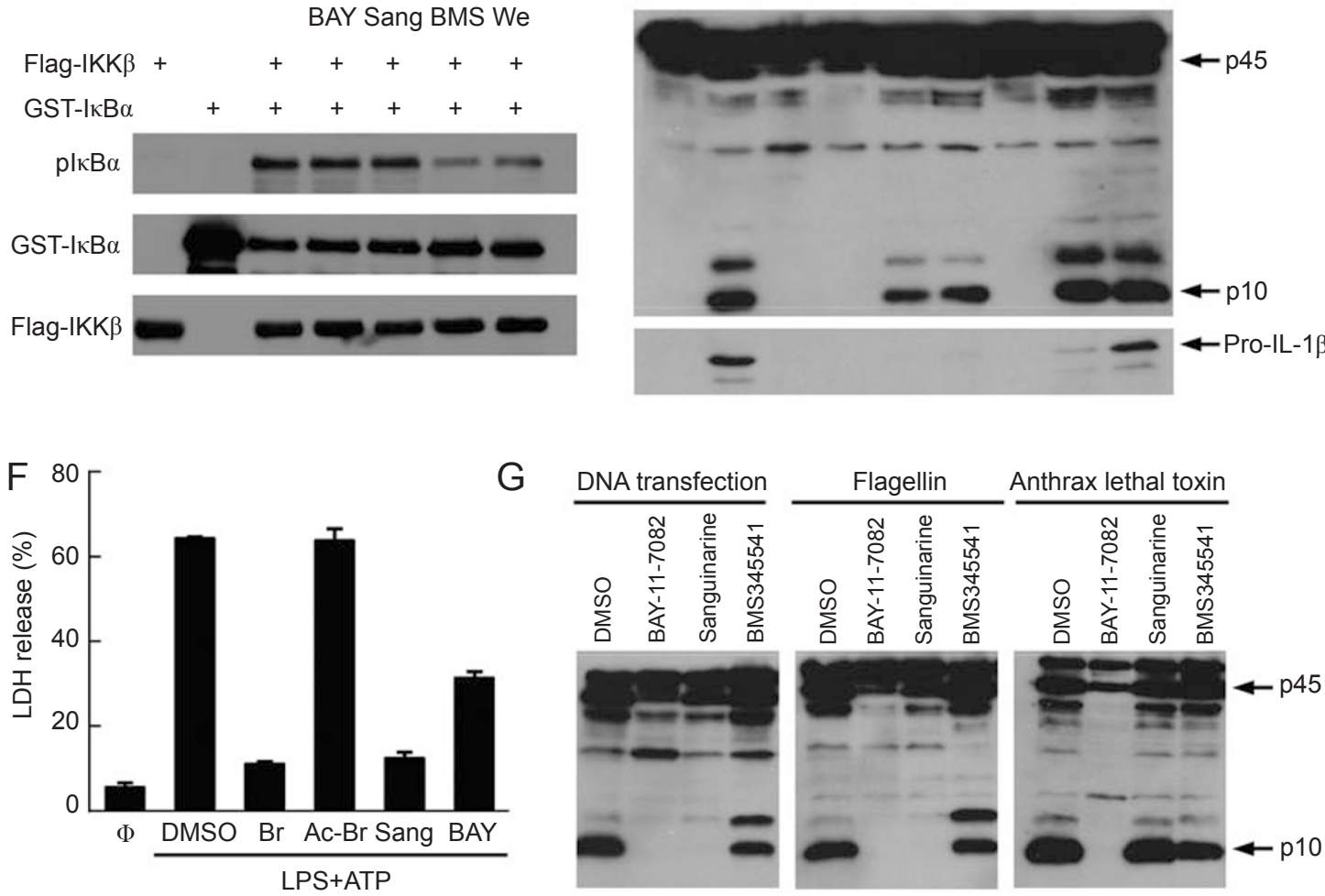

Figure 9 Block of bacterial infection-triggered inflammasome activation by bromoxone and potential pharmacological implications. (A-C) BMMs from C57BL/6 mice were infected with indicated bacterial pathogens in the presence or absence of bromoxone. Shown are caspase-1 immunoblots of the TCA precipitates of cell supernatants. (A) Legionella pneumophila (WT Lp02 strain or the type IV secretion-deficient dotA mutant Lp03 strain), MOI=10; (B) EPEC and its type three secretion-deficient mutant cfm-14, MOI=20; (C) S. flexneri, MOI=50. $200 \mu \mathrm{g} / \mathrm{ml}$ gentamicin was added $2 \mathrm{~h}$ after infection for (B) and (C). (D) Effects of BAY-11-7082, sanguinarine, BMS345541, and wedelolactone on IKK kinase activity. Recombinant GST-IKB $\alpha$ was subjected to in vitro phosphorylation by immunopurified IKK $\beta$ in the presence of indicated compounds (BAY, BAY-11-7082, 30 $\mu \mathrm{M}$; Sang, sanguinarine, $5 \mu \mathrm{M}$; BMS, BMS345541, $50 \mu \mathrm{M}$; We, wedelolactone, $40 \mu \mathrm{M})$. Shown are immunoblots of the phosphorylation reaction using indicated antibodies. (E) PMA-differentiated THP-1 cells were stimulated with LPS/ATP in the presence of indicated compounds. Shown are caspase- 1 and IL-1 $\beta$ immunoblots of cell supernatants. BAY, BAY-11-7082, $30 \mu \mathrm{M}$; Sang, sanguinarine, $5 \mu \mathrm{M}$; BMS, BMS345541, $50 \mu \mathrm{M}$; We, wedelolactone, $40 \mu \mathrm{M}$; Br, Bromoxone, $2.5 \mu \mathrm{M}$; MG, MG132, 50 $\mu \mathrm{M}$; Ac-Br, bromoxone acetate 2, $2.5 \mu \mathrm{M}$. (F) The LDH release of drug treated cells shown in (E). (G) BMMs from 129 mice were stimulated with DNA transfection (left panel), flagellin transfection (middle panel) or anthrax lethal toxin (right panel) in the presence of indicated compounds. Shown are caspase- 1 immunoblots of the TCA precipitates of cell supernatants. 
ing efforts of identifying the direct target(s) of bromoxone by affinity purification will most likely provide new components in the inflammasome pathway.

Anti-inflammation drugs are popularly used to treat conditions such as sepsis or some autoimmune diseases. For sepsis that usually involves or is exaggerated by extensive microbial infection, drugs capable of decreasing the systemic inflammation are often prescribed as a supplement to antibiotics treatment and surgical drainage/replacement of infected fluid. Several autoimmune diseases are caused by or associated with mutations in $N L R$ genes. For example, mutations in Nalp3 are associated with Muckle-Wells syndrome, familial cold urticaria, and chronic infantile neurological cutaneous and articular syndrome $[1,2]$. These diseases are caused by the upregulated inflammatory response characterized by excessive IL-1 $\beta$ secretion. Here, we identify bromoxone, as well as TAK-242, 5Z-7-oxozeaenol, sanguinarine and BAY-11-7082, all of which can simultaneously suppress both NF- $\mathrm{kB}-$ dependent gene transcription and inflammasome activation. In addition, bromoxone efficiently blocked caspase- 1 activation triggered by multiple types of bacterial infection; intraperitoneally injected bromoxone alleviated the loss of body weight for mice overloaded with LPS (data not shown). It is also worth mentioning that TAK-242 was under development for treating severe sepsis (Takeda Pharmaceutical Company Limited). Therefore, blocking caspase- 1 activation by targeting the NF- $\mathrm{KB}$ signaling pathway upstream of IKK might represent a potentially better strategy to develop new anti-inflammatory or antisepsis drugs. For Nalp3 gain-of-function autoimmune diseases, the present therapeutic strategy is mainly to inhibit the function of IL-1 $\beta$, such as using the IL-1 $\beta$ R antagonist anakinra ("Kineret" by Amgen Inc.). However, excessive IL-1 $\beta$ only partially contributes to the pathogenesis of these diseases, and disease symptoms observed in the mouse model (Nalp3 mutants knockin) are fully rescued by additional ASC knockout $[68,69]$. These results suggest that drugs targeting caspase-1 activation like bromoxone-type of inflammasome pathway inhibitors might be more effective in treating such autoimmune disorders. Finally, our studies also suggest a possible new strategy to develop anticaspase- 1 activation drugs using the existing large pool of NF- $\kappa \mathrm{B}$ inhibitors.

\section{Materials and Methods}

\section{Ethics statement}

All animal experiments were conducted following the "Ministry of Health" national guidelines for housing and care of laboratory animals and performed in accordance with institutional regulations after review and approval by the Institutional Animal Care and
Use Committee at National Institute of Biological Sciences.

\section{Plasmids, antibodies and reagents}

Pro-caspase-1, pro-IL-1 $\beta$, hNalp3 and ASC plasmids were kindly provided by Dr Xiaodong Wang (University of Texas Southwestern Medical Center, USA). AIM2 construct was a gift from Dr Katherine A Fitzgerald (University of Massachusetts Medical School, USA). cDNAs for IKK $\beta$, TAK1 and TAB1 have been recently described [62].

Antibodies for caspase-1, ІкB $\alpha$, Erk and $\mathrm{p} 65$ were obtained from Santa Cruz Biotechnology. JNK, phospho-JNK, phosphoI $\mathrm{B} \alpha$, phospho-Erk, $\gamma \mathrm{H} 2 \mathrm{~A} . \mathrm{X}$ and caspase-3 antibodies were purchased from Cell Signaling Technology. The rabbit polyclonal Nalp3 antibody was raised against Nalp3 pyrin domain (amino acids 1-94). The specificity of the antibody was validated using the Nalp $3^{-/}$mice. Other antibodies used in this study include: TAK1 (provided by Philip Cohen, University of Dundee), ASC (Alexis), KDEL (Stressgen), actin (Sigma), GM130 (BD), IL-1 1 (3ZD; Biological Resources Branch, National Cancer Institute, Frederick, MD, USA).

PAMPs and other stimuli used in this study were LPS (Sigma), $\mathrm{Pam}_{3} \mathrm{CSK}_{4}$ (InvivoGen), R848 (InvivoGen), ATP (Sigma), LeuLeu-OMe (Chem-Impex International), poly (dA:dT) (Sigma), Salmonella flagellin (InvivoGen), Profect P1 (Targeting Systems) and Nigericin (Calbiochem). All chemical inhibitors used for initial screen are listed in Supplementary information, Table S1 except for BAY-11-7082 (Biomol), sanguinarine (Hitsanns), BMS345541 (Sigma), MG132 (Sigma), MG115 (Calbiochem), 5Z-7-oxozeaenol (Calbiochem), JSH-23 (Tocris), CAPE (Tocris), TAK-242 (InvivoGen) and wedelolactone (Sigma). Cell culture products were from Invitrogen and all other chemicals were Sigma-Aldrich products unless noted.

\section{Synthesis of bromoxone and its analogues}

The synthesis of bromoxone and its analogues was based on previously reported protocols $[51,52]$, and the experimental details and structural validation data are included in Supplementary information, Data S1.

\section{siRNA transfection in THP-1 cells}

The SMARTpool siRNA targeting human TAK1 was purchased from Dharmacon. The scramble siRNA (5'-AAG GCC AGA CGC GAA UUA UdT dT-3') was used as a control. Lipofectamine RNAiMax (Invitrogen) was used for siRNA transfection. Briefly, $3 \times 10^{5}$ THP-1 cells were differentiated by $50 \mathrm{nM}$ PMA overnight (12-well form). $1 \mu \mathrm{l}$ of $20 \mu \mathrm{M}$ siRNA was then transfected by $2 \mu \mathrm{l}$ of lipofectamine RNAiMax for each well (The final siRNA concentration is $40 \mathrm{nM}$ ). At $60 \mathrm{~h}$ after transfection, the knockdown efficiency and caspase- 1 activation were monitored by western blot. Amaxa nucleofector transfection protocol essentially follows the manufacturer's instruction. At $48 \mathrm{~h}$ after transfection, THP-1 cells were differentiated by $50 \mathrm{nM}$ PMA for additional $12 \mathrm{~h}$ prior to the time of indicated assays.

\section{Cell culture and immunofluorescence microscopy}

$293 \mathrm{~T}$ and HeLa cells obtained from ATCC were grown in Dulbecco's modified Eagle's medium containing 10\% fetal bovine serum and $2 \mathrm{mM}$ L-glutamine at $37{ }^{\circ} \mathrm{C}$ in a $5 \% \mathrm{CO}_{2}$ incubator. THP-1 cells also obtained from ATCC were grown in RPMI 1640 
containing $10 \%$ fetal bovine serum and $2 \mathrm{mM}$ L-glutamine at 37 ${ }^{\circ} \mathrm{C}$. Normally, $50 \mathrm{nM}$ PMA was used to differentiate THP-1 cells for 24-36 h. Vigofect (Vigorous) was used for plasmid transfection in $293 \mathrm{~T}$ cells. BMMs derived from C57BL/6, TLR-deficient C57BL/10ScNJ (The Jackson Laboratory) and 129 mice were prepared as previously described [30]. Immortalized macrophage line derived from C57BL/6 mice was kindly provided by Dr Katherine A Fitzgerald.

Following the treatment, cells were fixed by $4 \%$ paraformaldehyde (Electron microscopy sciences) and permeabilized by $0.5 \%$ Triton X-100. After blocking with $1 \%$ BSA for $1 \mathrm{~h}$, cells were stained with indicated antibodies for 1-2 $\mathrm{h}$. After three washes with PBS, cells were stained with Alexa Fluor 488/546-conjugated secondary antibodies (Invitrogen) for another hour. DAPI (Invitrogen), Rhodamine-Phalloidin (Invitrogen), Mitotracker (Invitrogen), caspase-1 substrate FAM-YVAD-FMK (ImmunoChemistry Technologies) were used to stain nuclei, filamentous actin, mitochondria, and active caspase-1, respectively, following the manufacturer's instruction. Images were recorded on a Nikon fluorescence microscope.

\section{Caspase-1 activation and cell death stimulated by PAMPs} or bacterial infection

For PAMPs stimulation in the presence of ATP, PMA-differentiated THP-1 cells were stimulated with LPS ( $5 \mu \mathrm{g} / \mathrm{ml}), \mathrm{Pam}_{3} \mathrm{CSK}_{4}$ $(2 \mu \mathrm{g} / \mathrm{ml})$, or R848 $(2 \mu \mathrm{g} / \mathrm{ml})$ for 3-4 h and then pulsed with $5 \mathrm{mM}$ ATP for $30 \mathrm{~min}$ in serum-free medium. Procedures for LPS/nigericin stimulation, flagellin transfection, dsDNA transfection and anthrax lethal toxin induced caspase- 1 activation in THP-1 cells or BMMs were the same as previously described [14, 27, 28, 30]. For pathogen-triggered caspase-1 activation, BMMs were infected for $8 \mathrm{~h}$ by $S$. flexneri $2457 \mathrm{~T}$ expressing an adhesion factor (Afa E), $L$. pneumophila strains (Lp02 or type IV secretion-deficient Lp03), or EPEC E2348/69 strains (WT or type III secretion-deficient cfm14 mutant) at the MOI of 50, 10, 20, respectively. For Shigella and EPEC infections, gentamicin $(200 \mu \mathrm{g} / \mathrm{ml})$ was added to cultures $2 \mathrm{~h}$ after infection. To examine caspase- 1 activation, we collected supernatants of the above cell cultures and subjected them to TCA precipitation followed by anticaspase-1 immunoblotting. To measure cell death, we stained cells with Trypan blue in PBS for 2 min at room temperature, and then observed under a microscope. Alternatively, the supernatant was collected for the LDH assay (Promega) by following the manufacturer's protocol or analyzed by anti-HMGB1 immunoblotting. Each drug was added to cells upon exposure to the inflammatory stimuli. The concentration of each compound used was as follows unless noted: bromoxone (2.5 $\mu \mathrm{M})$, Ac-bromoxone $(2.5 \mu \mathrm{M}), \operatorname{MG} 132(50 \mu \mathrm{M}), \operatorname{MG} 115(50 \mu \mathrm{M})$, BMS345541 $(50 \mu \mathrm{M})$, wedelolactone $(40 \mu \mathrm{M})$, BAY-11-7082 (30 $\mu \mathrm{M})$, sanguinarine $(5 \mu \mathrm{M})$, TAK-242, $(20 \mu \mathrm{M})$, JSH-23 $(50 \mu \mathrm{M})$, CAPE $(50 \mu \mathrm{M}), 5 Z$-7-oxozeaenol $(1 \mu \mathrm{M})$ and etoposide $(40 \mu \mathrm{M})$.

Caspase-1 activation in cell extracts and reconstituted caspase-1 activation in 293 T cells

In vitro caspase- 1 activation in cell extracts was essentially similar as previously described [10]. Briefly, THP-1 cells were harvested and swelled in 3-4 volumes of ice-cold hypotonic buffer (20 mM HEPES-KOH (pH 7.5), $10 \mathrm{mM} \mathrm{KCl,} 1.5 \mathrm{mM} \mathrm{MgCl}_{2}, 1$ mM EDTA, $1 \mathrm{mM}$ EGTA, $0.1 \mathrm{mM}$ PMSF and the Roche protease inhibitor cocktail). The cellular membrane was then disrupted by
25 times of passage through a 22-gauge needle. Cell lysates were sequentially centrifuged at 3000 r.p.m. for $5 \mathrm{~min}$ and 13000 r.p.m. for $15 \mathrm{~min}$. Supernatants were incubated at $30{ }^{\circ} \mathrm{C}$, and caspase- 1 activation was measured by western blot.

AIM2-ASC-caspase-1 activation reconstituted in $293 \mathrm{~T}$ cells was performed as described [25]. In brief, $100 \mathrm{ng}$ procaspase-1, $3 \mu \mathrm{g}$ pro-IL-1 $\beta, 100 \mathrm{ng}$ ASC and $2 \mu \mathrm{g}$ AIM2 expression plasmid were transfected into $293 \mathrm{~T}$ cells (six-well plate format). The Nalp3-ASC-caspase-1 reconstitution experiment was performed similarly except that $2 \mu \mathrm{g}$ Nalp3 expression plasmid was used. Cells were harvested $26 \mathrm{~h}$ after transfection and lysed by RIPA buffer. The lysates were blotted using the IL-1 $\beta$ antibody.

\section{$N F-\kappa B$ pathway assays and ROS measurements}

PMA-differentiated THP-1 cells were stimulated with LPS $(5 \mu \mathrm{g} / \mathrm{ml}), \mathrm{Pam}_{3} \mathrm{CSK}_{4}(2 \mu \mathrm{g} / \mathrm{ml})$ or R848 $(2 \mu \mathrm{g} / \mathrm{ml})$ for $3 \mathrm{~h}$. Cells were lysed and analyzed by IL- $1 \beta$ immunoblotting. To examine I $\mathrm{B} \alpha$ degradation and $\mathrm{p} 65$ translocation, we stimulated cells with LPS $(5 \mu \mathrm{g} / \mathrm{ml})$ for 0.5 and $1 \mathrm{~h}$, respectively. Cell extract-based NF$\kappa \mathrm{B}$ reconstitution have been recently described [62], and 200-500 ng of TAK1/TAB1 complex immunopurified from 293T cells was added into cell extracts $(20 \mu \mathrm{l})$ to stimulate $\mathrm{I} \kappa \mathrm{B} \alpha$ phosphorylation. In vitro phosphorylation of recombinant GST-I $\kappa \mathrm{B} \alpha$ by immunopurified Flag-IKK $\beta$ was carried out as recently described [62].

ROS production was measured by using the ROS-specific fluorescent probe $2^{\prime} 7^{\prime}$-dichlorofluorescin diacetate $\left(\mathrm{H}_{2}\right.$ DCFDA; Sigma). Briefly, cells were loaded with $10 \mu \mathrm{M} \mathrm{H}_{2}$ DCFDA for 10 min, washed twice with PBS and then exposed to ATP for $30 \mathrm{~min}$ or other drug treatments as indicated. The live cells were subjected to FACS analysis for ROS production.

\section{Cell viability and IL-1 $\beta$ ELISA assays}

PMA-differentiated THP-1 cells were seeded into 96-well plates. After indicated stimulations or drug treatments, the culture media were collected for measuring the IL-1 $\beta$ level using the IL$1 \beta$ ELISA kit (Neobioscience Technology Company). To determine cell viability, we directly lysed the cells and then subjected them to CellTiter-Glo Luminescent Cell Viability Assay (Promega) to measure the level of ATP present in live cells. Both assays were performed essentially by following the manufacturer's instructions.

\section{Acknowledgments}

We are grateful to Dr Nicholas S Duesbery (Van Andel Institute, USA) for providing purified anthrax lethal toxin and protective antigen; Dr Katherine A Fitzgerald (University of Massachusetts Medical School, USA) for AIM2 constructs and the immortalized macrophage cell line; Dr Vishva Dixit (Genentech Inc., USA) for providing Nalp3 KO mice; Drs Xiaodong Wang and Lai Wang (University of Texas Southwestern Medical Center, USA) for procaspase-1, pro-IL-1 $\beta$ and ASC plasmids; Dr Brendan Kenny (University of Newcastle, UK) for EPEC E2348/69 wild-type and cfm14 mutant strains; Dr Zhao-qing Luo (Purdue University, USA) for Legionella Lp02 and Lp03 strains. We also thank Dr Jiang Zhou (Peking University, China) for high-resolution mass spectrum analysis and Dr Xiaodong Wang for encouragements on this study. We also thank members of Shao Lab for helpful discussions and technical assistance. 


\section{References}

1 Ting JP, Kastner DL, Hoffman HM. CATERPILLERs, pyrin and hereditary immunological disorders. Nat Rev Immunol 2006; 6:183-195.

2 Martinon F, Mayor A, Tschopp J. The inflammasomes: guardians of the body. Annu Rev Immunol 2009; 27:229-265.

3 Dinarello CA. Interleukin-1 beta, interleukin-18, and the interleukin-1 beta converting enzyme. Ann N Y Acad Sci 1998; 856:1-11.

4 Beutler BA. TLRs and innate immunity. Blood 2009; 113:1399-1407.

5 Kumar H, Kawai T, Akira S. Pathogen recognition in the innate immune response. Biochem J 2009; 420:1-16.

6 West AP, Koblansky AA, Ghosh S. Recognition and signaling by toll-like receptors. Annu Rev Cell Dev Biol 2006; 22:409437.

7 Hayden MS, Ghosh S. Shared principles in NF-kappaB signaling. Cell 2008; 132:344-362.

8 Vallabhapurapu S, Karin M. Regulation and function of NFkappaB transcription factors in the immune system. Annu Rev Immunol 2009; 27:693-733.

9 Miller DK, Ayala JM, Egger LA, et al. Purification and characterization of active human interleukin-1 beta-converting enzyme from THP.1 monocytic cells. J Biol Chem 1993; 268:18062-18069.

10 Martinon F, Burns K, Tschopp J. The inflammasome: a molecular platform triggering activation of inflammatory caspases and processing of proIL-beta. Mol Cell 2002; 10:417-426.

11 Yamin TT, Ayala JM, Miller DK. Activation of the native 45$\mathrm{kDa}$ precursor form of interleukin-1-converting enzyme. $J$ Biol Chem 1996; 271:13273-13282.

12 Shaw MH, Reimer T, Kim YG, Nunez G. NOD-like receptors (NLRs): bona fide intracellular microbial sensors. Curr Opin Immunol 2008; 20:377-382.

13 Ting JP, Willingham SB, Bergstralh DT. NLRs at the intersection of cell death and immunity. Nat Rev Immunol 2008; 8:372-379.

14 Mariathasan S, Weiss DS, Newton K, et al. Cryopyrin activates the inflammasome in response to toxins and ATP. Nature 2006; 440:228-232.

15 Sutterwala FS, Ogura Y, Szczepanik M, et al. Critical role for NALP3/CIAS1/Cryopyrin in innate and adaptive immunity through its regulation of caspase-1. Immunity 2006; 24:317327.

16 Cassel SL, Eisenbarth SC, Iyer SS, et al. The Nalp3 inflammasome is essential for the development of silicosis. Proc Natl Acad Sci USA 2008; 105:9035-9040.

17 Dostert C, Petrilli V, Van Bruggen R, Steele C, Mossman BT, Tschopp J. Innate immune activation through Nalp3 inflammasome sensing of asbestos and silica. Science 2008; 320:674-677.

18 Eisenbarth SC, Colegio OR, O'Connor W, Sutterwala FS, Flavell RA. Crucial role for the Nalp3 inflammasome in the immunostimulatory properties of aluminium adjuvants. Nature 2008; 453:1122-1126.

19 Halle A, Hornung V, Petzold GC, et al. The NALP3 inflammasome is involved in the innate immune response to amyloid-beta. Nat Immunol 2008; 9:857-865.
20 Hornung V, Bauernfeind F, Halle A, et al. Silica crystals and aluminum salts activate the NALP3 inflammasome through phagosomal destabilization. Nat Immunol 2008; 9:847-856.

21 Martinon F, Petrilli V, Mayor A, Tardivel A, Tschopp J. Goutassociated uric acid crystals activate the NALP3 inflammasome. Nature 2006; 440:237-241.

22 Kanneganti TD, Ozoren N, Body-Malapel M, et al. Bacterial RNA and small antiviral compounds activate caspase-1 through cryopyrin/Nalp3. Nature 2006; 440:233-236.

23 Franchi L, Eigenbrod T, Nunez G. Cutting edge: TNF-alpha mediates sensitization to ATP and silica via the NLRP3 inflammasome in the absence of microbial stimulation. J Immunol 2009; 183:792-796.

24 Greten FR, Arkan MC, Bollrath J, et al. NF-kappaB is a negative regulator of IL-1beta secretion as revealed by genetic and pharmacological inhibition of IKKbeta. Cell 2007; 130:918931.

25 Hornung V, Ablasser A, Charrel-Dennis M, et al. AIM2 recognizes cytosolic dsDNA and forms a caspase-1-activating inflammasome with ASC. Nature 2009; 458:514-518.

26 Kanneganti TD, Lamkanfi M, Kim YG, et al. Pannexin-1mediated recognition of bacterial molecules activates the cryopyrin inflammasome independent of Toll-like receptor signaling. Immunity 2007; 26:433-443.

27 Miao EA, Alpuche-Aranda CM, Dors M, et al. Cytoplasmic flagellin activates caspase-1 and secretion of interleukin 1beta via Ipaf. Nat Immunol 2006; 7:569-575.

28 Muruve DA, Petrilli V, Zaiss AK, et al. The inflammasome recognizes cytosolic microbial and host DNA and triggers an innate immune response. Nature 2008; 452:103-107.

29 Lightfield KL, Persson J, Brubaker SW, et al. Critical function for Naip5 in inflammasome activation by a conserved carboxy-terminal domain of flagellin. Nat Immunol 2008; 9:1171-1178.

30 Boyden ED, Dietrich WF. Nalp1b controls mouse macrophage susceptibility to anthrax lethal toxin. Nat Genet 2006; 38:240244.

31 Burckstummer T, Baumann C, Bluml S, et al. An orthogonal proteomic-genomic screen identifies AIM2 as a cytoplasmic DNA sensor for the inflammasome. Nat Immunol 2009; 10:266-272.

32 Fernandes-Alnemri T, Yu JW, Datta P, Wu J, Alnemri ES. AIM2 activates the inflammasome and cell death in response to cytoplasmic DNA. Nature 2009; 458:509-513.

33 Pelegrin P, Surprenant A. Pannexin-1 mediates large pore formation and interleukin-1beta release by the ATP-gated P2X7 receptor. EMBO J 2006; 25:5071-5082.

34 Roberts TL, Idris A, Dunn JA, et al. HIN-200 proteins regulate caspase activation in response to foreign cytoplasmic DNA. Science 2009; 323:1057-1060.

35 Franchi L, Amer A, Body-Malapel M, et al. Cytosolic flagellin requires Ipaf for activation of caspase-1 and interleukin 1beta in salmonella-infected macrophages. Nat Immunol 2006; 7:576-582.

36 Mariathasan S, Newton K, Monack DM, et al. Differential activation of the inflammasome by caspase- 1 adaptors ASC and Ipaf. Nature 2004; 430:213-218.

37 Amer A, Franchi L, Kanneganti TD, et al. Regulation of Legionella phagosome maturation and infection through flagel- 
lin and host Ipaf. $J$ Biol Chem 2006; 281:35217-35223.

38 Molofsky AB, Byrne BG, Whitfield NN, et al. Cytosolic recognition of flagellin by mouse macrophages restricts Legionella pneumophila infection. J Exp Med 2006; 203:1093-1104.

39 Ren T, Zamboni DS, Roy CR, Dietrich WF, Vance RE. Flagellin-deficient Legionella mutants evade caspase-1- and Naip5mediated macrophage immunity. PLoS Pathog 2006; 2:e18.

40 Franchi L, Stoolman J, Kanneganti TD, Verma A, Ramphal R, Nunez G. Critical role for Ipaf in Pseudomonas aeruginosainduced caspase-1 activation. Eur J Immunol 2007; 37:30303039.

41 Miao EA, Ernst RK, Dors M, Mao DP, Aderem A. Pseudomonas aeruginosa activates caspase 1 through Ipaf. Proc Natl Acad Sci USA 2008; 105:2562-2567.

42 Sutterwala FS, Mijares LA, Li L, Ogura Y, Kazmierczak BI, Flavell RA. Immune recognition of Pseudomonas aeruginosa mediated by the IPAF/NLRC4 inflammasome. $J$ Exp Med 2007; 204:3235-3245.

43 Zamboni DS, Kobayashi KS, Kohlsdorf T, et al. The Bircle cytosolic pattern-recognition receptor contributes to the detection and control of Legionella pneumophila infection. Nat Immunol 2006; 7:318-325.

44 Suzuki T, Franchi L, Toma C, et al. Differential regulation of caspase-1 activation, pyroptosis, and autophagy via Ipaf and ASC in Shigella-infected macrophages. PLoS Pathog 2007; 3:e111.

45 Willingham SB, Bergstralh DT, O'Connor W, et al. Microbial pathogen-induced necrotic cell death mediated by the inflammasome components CIAS1/cryopyrin/NLRP3 and ASC. Cell Host Microbe 2007; 2:147-159.

46 Higa T, Okuda RK, Severns RM, et al. Unprecedented constituents of a new species of acorn worm. Tetrahedron 1987; 43:1063-1070.

47 Degterev A, Huang Z, Boyce M, et al. Chemical inhibitor of nonapoptotic cell death with therapeutic potential for ischemic brain injury. Nat Chem Biol 2005; 1:112-119.

48 Cassidy-Stone A, Chipuk JE, Ingerman E, et al. Chemical inhibition of the mitochondrial division dynamin reveals its role in Bax/Bak-dependent mitochondrial outer membrane permeabilization. Dev Cell 2008; 14:193-204.

49 Fernandes-Alnemri T, Wu J, Yu JW, et al. The pyroptosome: a supramolecular assembly of ASC dimers mediating inflammatory cell death via caspase-1 activation. Cell Death Differ 2007; 14:1590-1604.

$50 \mathrm{Yu}$ JW, Wu J, Zhang Z, et al. Cryopyrin and pyrin activate caspase-1, but not NF-kappaB, via ASC oligomerization. Cell Death Differ 2006; 13:236-249.

51 Porco JA, Jr., Su S, Lei X, Bardhan S, Rychnovsky SD. Total synthesis and structure assignment of (+)-hexacyclinol. Angew Chem Int Ed Engl 2006; 45:5790-5792.

52 Lei X, Johnson RP, Porco JA, Jr. Total synthesis of the ubiquitin-activating enzyme inhibitor (+)-panepophenanthrin. Angew Chem Int Ed Engl 2003; 42:3913-3917.

53 Lamkanfi M, Mueller JL, Vitari AC, et al. Glyburide inhibits the Cryopyrin/Nalp3 inflammasome. J Cell Biol 2009; 187:61-70.

54 Mariathasan S, Monack DM. Inflammasome adaptors and sensors: intracellular regulators of infection and inflammation.
Nat Rev Immunol 2007; 7:31-40.

55 Bauernfeind FG, Horvath G, Stutz A, et al. Cutting edge: NFkappaB activating pattern recognition and cytokine receptors license NLRP3 inflammasome activation by regulating NLRP3 expression. J Immunol 2009; 183:787-791.

56 Okamoto M, Liu W, Luo Y, et al. Constitutively active inflammasome in human melanoma cells mediating autoinflammation via caspase-1 processing and secretion of interleukin1beta. J Biol Chem 2010; 285:6477-6488.

57 Feldmeyer L, Keller M, Niklaus G, Hohl D, Werner S, Beer HD. The inflammasome mediates UVB-induced activation and secretion of interleukin-1beta by keratinocytes. Curr Biol 2007; 17:1140-1145.

58 Takashima K, Matsunaga N, Yoshimatsu M, et al. Analysis of binding site for the novel small-molecule TLR4 signal transduction inhibitor TAK-242 and its therapeutic effect on mouse sepsis model. Br J Pharmacol 2009; 157:1250-1262.

59 Kawamoto T, Ii M, Kitazaki T, Iizawa Y, Kimura H. TAK-242 selectively suppresses Toll-like receptor 4-signaling mediated by the intracellular domain. Eur J Pharmacol 2008; 584:4048.

60 Burke JR, Pattoli MA, Gregor KR, et al. BMS-345541 is a highly selective inhibitor of I kappa B kinase that binds at an allosteric site of the enzyme and blocks NF-kappa B-dependent transcription in mice. J Biol Chem 2003; 278:1450-1456.

61 Kobori M, Yang Z, Gong D, et al. Wedelolactone suppresses LPS-induced caspase-11 expression by directly inhibiting the IKK complex. Cell Death Differ 2004; 11:123-130.

$62 \mathrm{Ge} \mathrm{J}, \mathrm{Xu} \mathrm{H}, \mathrm{Li}$, et al. A Legionella type IV effector activates the NF- $\kappa \mathrm{B}$ pathway by phosphorylating the I $\mathrm{B}$ family of inhibitors. Proc Natl Acad Sci USA 2009; 106:13725-13730.

63 Horwitz MA. Formation of a novel phagosome by the Legionnaires' disease bacterium (Legionella pneumophila) in human monocytes. J Exp Med 1983; 158:1319-1331.

64 Isberg RR, O'Connor TJ, Heidtman M. The Legionella pneumophila replication vacuole: making a cosy niche inside host cells. Nat Rev Microbiol 2009; 7:13-24.

65 Pierce JW, Schoenleber R, Jesmok G, et al. Novel inhibitors of cytokine-induced IkappaBalpha phosphorylation and endothelial cell adhesion molecule expression show antiinflammatory effects in vivo. J Biol Chem 1997; 272:2109621103.

66 Chaturvedi MM, Kumar A, Darnay BG, Chainy GB, Agarwal S, Aggarwal BB. Sanguinarine (pseudochelerythrine) is a potent inhibitor of NF-kappaB activation, IkappaBalpha phosphorylation, and degradation. J Biol Chem 1997; 272:3012930134.

67 Zhou R, Tardivel A, Thorens B, Choi I, Tschopp J. Thioredoxin-interacting protein links oxidative stress to inflammasome activation. Nat Immunol 2010; 11:136-140.

68 Meng G, Zhang F, Fuss I, Kitani A, Strober W. A mutation in the Nlrp3 gene causing inflammasome hyperactivation potentiates Th17 cell-dominant immune responses. Immunity 2009; 30:860-874.

69 Brydges SD, Mueller JL, McGeough MD, et al. Inflammasome-mediated disease animal models reveal roles for innate but not adaptive immunity. Immunity 2009; 30:875-887.

(Supplementary information is linked to the online version of the paper on the Cell Research website.) 